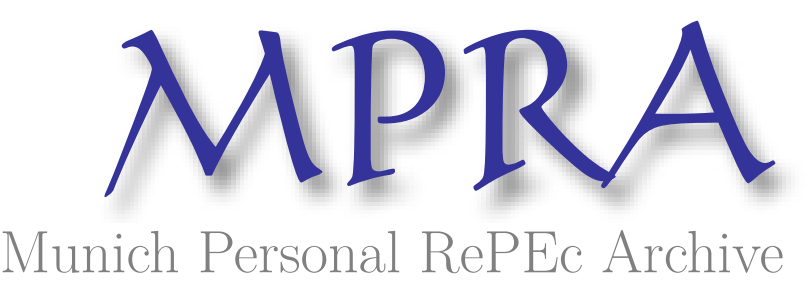

Hedging emerging market stock prices with oil, gold, VIX, and bonds: A comparison between DCC, ADCC and GO-GARCH

Syed Abul, Basher and Perry, Sadorsky

6 December 2015

Online at https://mpra.ub.uni-muenchen.de/68231/

MPRA Paper No. 68231, posted 08 Dec 2015 09:21 UTC 


\title{
Hedging emerging market stock prices with oil, gold, VIX, and bonds: A comparison between DCC, ADCC and GO-GARCH
}

\author{
Syed Abul Basher \\ Department of Economics, East West \\ University, Plot No-A/2, Aftabnagar Main \\ Road, Dhaka 1219, Bangladesh \\ and \\ Fikra Research \& Policy, \\ P.O. Box 2664, Doha, Qatar \\ Email: syed.basher@gmail.com
}

\author{
Perry Sadorsky \\ Schulich School of Business \\ York University \\ 4700 Keele Street \\ Toronto, Ontario, Canada \\ M3J 1P3 \\ Email: psadorsk@ schulich.yorku.ca \\ Telephone: +14167365067 \\ Fax: +1 4167365687
}

October 2014, revised June 2015

\begin{abstract}
While much research uses multivariate GARCH to model volatility dynamics and risk measures, one particular type of multivariate GARCH model, GO-GARCH, has been underutilized. This paper uses DCC, ADCC and GO-GARCH to model volatilities and conditional correlations between emerging market stock prices, oil prices, VIX, gold prices and bond prices. A rolling window analysis is used to construct out-of-sample onestep-ahead forecasts of dynamic conditional correlations and optimal hedge ratios. In most of the situations we study, oil is the best asset to hedge emerging market stock prices. Hedge ratios from the ADCC model are preferred (most effective) for hedging emerging market stock prices with oil, VIX, or bonds. Hedge ratios estimated from the GO-GARCH are most effective for hedging emerging market stock prices with gold in some instances. These results are reasonably robust to choice of model refits, forecast length and distributional assumptions.
\end{abstract}

Jel Classification: G15, Q43

Keywords: Emerging market stock prices; DCC-GARCH, GO-GARCH; Oil prices; hedging Acknowledgements: We thank three anonymous reviewers for helpful comments. 


\section{Introduction}

Modelling the volatility dynamics between oil and other assets is an important and timely topic to study because recent developments in increased integration between financial markets and the financialization of commodity markets are providing investors with new ways to diversify, hedge and risk manage their investment portfolios (eg. Erb and Harvey, 2006; Domanski and Heath, 2007; Dwyer et al., 2011; Silvennoinen and Thorp, 2013; Tang and Xiong, 2012; Vivian and Wohar, 2012). To date, most of the research on volatility dynamics, correlations and hedge ratios between oil and other assets has used multivariate GARCH (generalized autoregressive conditional heteroskedasticity) models like BEKK (Baba, Engle, Kraft, and Kroner, 1990), DCC (dynamic conditional correlation, Engle, 2002) or VARMA-GARCH (Ling and McAleer, 2003).

Estimating multivariate GARCH models on large data sets does, however, pose challenges. For example, the BEKK model can have a poorly behaved likelihood function which makes estimation difficult, especially for models with more than two variables. The vectorized $(\mathrm{VECH})$ model has a large number of free parameters which makes it impractical for models with more than two variables. The basic problem is that as the number of estimated parameters increases, the likelihood function flattens making optimization very difficult, or in some cases impossible. Restricted correlation models, like constant conditional correlation (CCC), dynamic conditional correlation (DCC) or asymmetric DCC (ADCC) are designed to address some of the problems encountered with BEKK and VECH type models and still retain analytical tractability for large data sets. One of the biggest challenges in multivariate GARCH modeling is finding a tradeoff 
between generality and feasibility, a tradeoff that is often referred to as "The curse of dimensionality" (eg. Bauwens et al., 2006).

Another approach to multivariate GARCH modelling is to assume that the returns are generated by a set of unobserved underlying factors that are conditionally heteroskedastic. This approach gives rise to factor GARCH models (Engle et al., 1990). The factors may be correlated making it difficult to determine them. In the orthogonal GARCH (OGARCH) model of Alexander (2001) which builds on the work of Ding (1994), uncorrelated and independent factors are used. In OGARCH, covariance matrices are obtained from univariate GARCH estimates of the variances of principle components and a matrix of rescaled factor weights obtained from the principal components analysis. Ding's approach was to use all of the principal comments while Alexander's approach is to use a small number of principal components. Alexander's approach is simple enough that it can be estimated using a spreadsheet. The OGARCH has several advantages. First, by using principal components to estimate the factors, the computational burden can be greatly reduced. In a system of $\mathrm{k}$ variables, a $\mathrm{k} x \mathrm{k}$ GARCH covariance matrix can be obtained from m univariate GARCH processes of principal components where the number of principal components $(\mathrm{m})$ is less than $\mathrm{k}$. In fact, $\mathrm{m}$ can be considerably smaller than k. In a highly correlated system of equations, only a small number of principal components are required in order to provide a high degree of accuracy. Second, these matrices are positive definite avoiding some of the difficulties encountered with other estimation techniques. Building on the work of Alexander (2001) Van der Weide (2002) proposed a generalized OGARCH model (GO-GARCH) which consists of a set of 
conditionally uncorrelated univariate GARCH processes and a linear map that relates these components to the observed data. The OGARCH model is a special case of the GOGARCH model where the linear map is orthogonal. GO-GARCH assumes that the unobserved underlying factors are uncorrelated and independent; as a result, the dynamics of the marginal density parameters of those factors may be estimated separately and in parallel, without having to be restricted to any particular single model or dynamics (Ghalanos et al., 2012). It is for this reason (i.e., the ability to model the margins separately), the GO-GARCH model provides much more flexibility than competing multivariate GARCH models ${ }^{1}$. We conjecture that GO-GARCH is underutilized because DCC is very easy to estimate for a large number of assets and intuitive to explain. The first version of GO-GARCH, van der Weide (2002), appeared around the same time as DCC and used the maximum likelihood approach in estimation. This was infeasible for all but small data sets. Subsequent improvements in GO-GARCH focused on estimation with many assets (van der Weide, 2006 and Boswijk and van der Weide, 2011). DCC captures 1) persistence in volatility and correlation and 2) time-varying correlation, but does not capture spill-over effects in volatility nor is DCC closed under linear transformation. GO-GARCH satisfies all four of these requirements but has, until recently, been more difficult to estimate.

\footnotetext{
${ }^{1}$ The GO-GARCH is nested within the BEKK. If one is working with a small data set of say two variables, then BEKK may be more desirable than either GO-GARCH or DCC. Caporin and McAleer (2012) provide strong arguments for why BEKK is preferable over DCC for small data sets. The difficulty, however, is estimation with large data sets. Here one encounters the "Curse of dimensionality". BEKK suffers from convergence problems for data sets larger than two variables. In our case, we have a five variable data set, which rules out BEKK type models.
} 
This paper makes several important contributions to the literature. First, while many existing studies use DCC-GARCH models to estimate optimal hedge ratios, this current paper compares the optimal hedge ratios obtained from DCC type models with those obtained from GO-GARCH. This provides a more complete understanding of how optimal hedge ratios vary between different multivariate GARCH specifications. Second, GARCH models are used to construct one-period-ahead hedge ratios. This differs from many other studies which use the current hedge ratio as a proxy for the next period hedge ratio. The one-step-ahead optimal hedge ratios are constructed using a rolling window analysis which takes into account changing variability in the data. Third, this paper uses a more varied and relevant data set to construct cross-hedges for emerging market stock prices. Hedge ratios are computed between emerging market stock prices and the futures prices of oil, gold, and US bonds. In addition the possibility of cross-hedging emerging market stock prices with the VIX volatility index is also investigated.The following sections of the paper set out the relevant literature, empirical methodology, data, empirical results, robustness analysis, and the conclusions.

\section{Relevant literature}

We recognize that GARCH models are widely used to model asset price volatility dynamics $^{2}$. Since hedging is our focus in this paper we limit our discussions to a short

\footnotetext{
2 There is a large and growing literature looking at the volatility dynamics between equities and various commodities (eg. Malik and Hammoudeh, 2007; Malik and Ewing, 2009; Hakem and McAleer, 2010; Filis et al, 2011; Chang et al., 2013; Mollick and Assefa, 2013; Hwan et al., 2013; Guesmi and Fattoumi, 2014) or between different commodities (eg. Hammoudeh and Yuan, 2008; Hammoudeh et al., 2011; Creti et al., 2013; Choi and Hammoudeh, 2010; Zhang et al., 2009; Du et al., 2011; Serra, 2011; Serra et al., 2011; Nazlioglu et al., 2013; Mensi et al., 2013; Mensi et al., 2014; Beckmann and Czudaj, 2014).
} 
review of relevant papers that focus directly on hedging equities with oil and other related commodities.

Chang et al. (2010) study the ability to hedge oil and gasoline spot prices with their respective futures prices during bull and bear markets. Eight popular models (OLS, multivariate $\mathrm{GARCH}$, error correction, and state space) are used to construct measures of hedging effectiveness. Their results show that hedging effectiveness is higher in bull markets. For the out-of-sample analysis, CCC-GARCH and CCC (constant conditional correlation) error correction models are ranked highest on hedging effectiveness.

Arouri et al. (2011a) estimate bivariate GARCH models using weekly data from January 1998 to December 2009 to investigate volatility spillovers between oil and stock market sectors in the US and Europe. They find evidence of a spillover effect from oil to stock markets in Europe and a bidirectional spillover effect between oil and US stock market sectors. For a particular equity/oil hedge, optimal hedge ratios computed from different GARCH models are very similar. Equity/oil optimal hedge ratios for the DJ Stoxx Europe 600 range between 0.174 and 0.223 . The S\&P 500/oil optimal hedge ratios range between 0.142 and 0.199 . Optimal hedge ratios vary across industry sectors. For example the financial sector in Europe has an optimal hedge ratio of 0.001 compared to the optimal hedge ratio in the European utilities sector of 0.176.

Arouri et al. (2011b) estimate bivariate GARCH models over the period 2005 to 2010 to determine return and volatility transmission between oil prices and stock markets in the 
Gulf Cooperation Council (GCC) countries. They find evidence of spillovers between these markets. Optimal hedge ratios between GCC equity markets and oil range from a low of 0.078 (Saudi Arabia) to a high of 0.429 (Oman).

Arouri et al. (2012) use VAR-GARCH models to model volatility dynamics between European equity markets and oil. Analysis is conducted using weekly data from January 1998 to December 2009. They find evidence of volatility spillovers between oil prices and sector stock returns. Optimal hedge ratios between equities and oil vary considerably from a low of 0.001 (Financials) to a high of 0.200 (DJ Stoxx Europe 600).

Chang et al. (2011) investigate the usefulness of BEKK, CCC, DCC, and VARMAGARCH to hedge crude oil spot prices with crude oil futures prices. Both BRENT and WTI crude oil prices are considered. They present evidence that hedge ratios are timevarying. Hedging effectiveness calculations reveal that hedges calculated from DCC are the best while hedges calculated from BEKK are the worst.

Sadorsky (2012) uses multivariate GARCH(1,1) models to investigate volatility dynamics between the stock prices of clean energy companies, technology companies and oil prices over the period January 1, 2001 to December 31, 2010. The stock prices of clean energy companies correlates more highly with technology stock prices than with oil prices. The average optimal hedge ratio between clean energy companies and oil is 0.20 . The rather large standard deviation of 0.19 and range (maximum $=0.79$, minimum -0.23 ) indicates that the hedge should be adjusted frequently. 
Pan et al. (2014) use a regime switching asymmetric DCC (RS-ADCC) model to evaluate hedging effectiveness between crude oil and related petroleum products like heating oil and gasoline. The BEKK has the highest hedging effectiveness for hedging crude futures with gasoline futures. The RS-ADCC produces the highest hedging effectiveness for hedging crude with heating oil.

Lin et al. (2014) use VAR-GARCH and DCC-GARCH models to investigate the volatility dynamics and hedge ratios between equity prices in Ghana and Nigeria and oil prices. They find that the optimal hedge ratio for Ghana varies between 0.51 and 0.40 while the optimal hedge ratio for Nigeria ranges between 0.56 and 0.50

Sadorsky (2014a) uses multivariate GARCH models to study the volatility dynamics between emerging market stock prices, oil prices, copper prices, and wheat prices. The daily data set covers the period January 3, 2000 to June 29, 2012. On average, oil provides the cheapest hedge for emerging market stock prices $(0.12)$ while copper is the most expensive $(0.25)$ but since the hedge ratios display considerable variability, these hedges should be routinely monitored and updated is necessary.

Sadorsky (2014b) uses DCC and CCC GARCH models estimated on weekly data to model volatility and conditional correlations between the Dow Jones socially responsible investment (SRI) equity portfolio, gold and oil. SRI share similar statistical properties with the S\&P 500 and as a result, SRI investors can expect to pay a similar amount to 
hedge their investment with oil or gold as investors in the S\&P 500. For example, the average hedge ratio between SRI and oil is 0.05 while the average hedge ratio between the S\&P 500 and oil is 0.07 .

From the existing literature we learn several things. First, this research demonstrates a keen interest in hedging equities with commodities and in particular oil. Many papers focus exclusively on the equity oil hedge and while this is useful it fails to provide a balanced perspective on how equity - oil hedges compare with the ability of other assets to hedge equities. Second, many authors choose a particular GARCH model (eg. DCCGARCH or VARMA-GARCH) and then present results from their chosen model without providing a comparison of how one model compares to another. Comparing results from different GARCH models is useful in deepening our understanding of how hedge ratios vary by estimation technique. Third, much of the existing literature calculates in-sample hedge ratios and portfolio weights. While in-sample analysis is useful for understanding model fit, it is not the most useful approach if one is interested in forward looking decision making. For forecasting, out-of-sample analysis is more informative.

\section{Empirical models}

In this paper, the DCC model of Engle (2002), the ADCC model of Cappiello et al. (2006) and the GO-GARCH model of van der Weide (2002) are used to model the volatility dynamics, conditional correlations and hedge ratios between emerging market stock prices, oil prices, the VIX, gold prices, and bond prices. 
Let $r_{t}$ be a $n \times 1$ vector of asset returns. An AR(1) process for $r_{t}$ conditional on the information set $I_{\mathrm{t}-1}$ can be written as:

$$
r_{t}=\mu+a r_{t-1}+\varepsilon_{t}
$$

The residuals are modelled as:

$$
\varepsilon_{t}=H_{t}^{1 / 2} z_{t}
$$

$H_{t}$ is the conditional covariance matrix of $r_{t}$ and $z_{t}$ is a $n \times 1$ i.i.d random vector of errors.

The Engle (2002) dynamic conditional correlation (DCC) model is estimated in two steps. In the first step, the GARCH parameters are estimated. In the second step, the conditional correlations are estimated.

$$
H_{t}=D_{t} R_{t} D_{t}
$$

$H_{t}$ is a $n x$ conditional covariance matrix, $R_{t}$ is the conditional correlation matrix, and $D_{t}$ is a diagonal matrix with time-varying standard deviations on the diagonal.

$$
\begin{gathered}
D_{t}=\operatorname{diag}\left(h_{1, t}^{1 / 2}, \ldots h_{n, t}^{1 / 2}\right) \\
R_{t}=\operatorname{diag}\left(q_{1, t}^{-1 / 2}, \ldots q_{n, t}^{-1 / 2}\right) Q_{t} \operatorname{diag}\left(q_{1, t}^{-1 / 2}, \ldots q_{n, t}^{-1 / 2}\right)
\end{gathered}
$$

The expressions for $\mathrm{h}$ are univariate $\mathrm{GARCH}$ models ( $\mathrm{H}$ is a diagonal matrix). For the GARCH(1,1) model the elements of $\mathrm{H}_{\mathrm{t}}$ can be written as:

$$
h_{i, t}=\omega_{i}+\alpha_{i} \varepsilon_{i, t-1}^{2}+\beta_{i} h_{i, t-1}
$$

$\mathrm{Q}_{\mathrm{t}}$ is a symmetric positive definite matrix.

$$
Q_{t}=\left(1-\theta_{1}-\theta_{2}\right) \bar{Q}+\theta_{1} z_{t-1} z_{t-1}^{\prime}+\theta_{2} Q_{t-1}
$$


$\bar{Q}$ is the nxn unconditional correlation matrix of the standardized residuals $\mathrm{z}_{\mathrm{i}, \mathrm{t}}\left(\mathrm{z}_{\mathrm{i}, \mathrm{t}}=\right.$ $\left.\varepsilon_{\mathrm{i}, t} / \sim_{\mathrm{h}_{\mathrm{i}, \mathrm{t}}}\right)$. The parameters $\theta_{1}$ and $\theta_{2}$ are non-negative. These parameters are associated with the exponential smoothing process that is used to construct the dynamic conditional correlations. The DCC model is mean reverting as long as $\theta_{1}+\theta_{2}<1$. The correlation estimator is,

$$
\rho_{i, j, t}=\frac{q_{i, j, t}}{\sqrt{q_{i, i, t} q_{j, j, t}}}
$$

Cappiello et al. (2006) build on the DCC model and the asymmetric GARCH model of Glosten et al., (1993) by adding in an asymmetric term and create the Asymmetric DCC (ADCC) model.

$$
h_{i, t}=\omega_{i}+\alpha_{i} \varepsilon_{i, t-1}^{2}+\beta_{i} h_{i, t-1}+d_{i} \varepsilon_{i, t-1}^{2} I\left(\varepsilon_{i, t-1}\right)
$$

The indicator function $\mathrm{I}\left(\varepsilon_{\mathrm{i}, \mathrm{t}-1}\right)$ is equal to one if $\varepsilon_{\mathrm{i}, \mathrm{t}-1}<0$ and 0 otherwise. For this specification, a positive value for $\mathrm{d}$ means that negative residuals tend to increase the variance more than positive ones. The asymmetric effect or "leverage effect" is designed to capture an often observed characteristic of financial assets that an unexpected drop in asset prices tends to increase volatility more than an unexpected increase in asset prices of the same magnitude. This can be interpreted to mean that bad news increases volatility more than good news.

For the ADCC model, the dynamics of $\mathrm{Q}$ are given by:

$$
\begin{gathered}
Q_{t}=\left(\bar{Q}-A^{\prime \bar{Q}} A-B^{\prime \bar{Q}} B-G^{\prime \bar{Q}^{-}} G\right)+A^{\prime z_{t-1} z_{t-1}^{\prime} A} \\
+B^{\prime} Q_{t-1} B+G^{\prime} z_{t}^{-} z_{t}^{\prime} G
\end{gathered}
$$


In the above equation $\mathrm{A}, \mathrm{B}$ and $\mathrm{G}$ are $\mathrm{n} \times \mathrm{n}$ parameter matrices and $z_{t}^{-}$are zero-threshold standardized errors which are equal to $\mathrm{z}_{\mathrm{t}}$ when less than zero and zero otherwise. $\bar{Q}$ and $\bar{Q}^{-}$are the unconditional matrices of $\mathrm{z}_{\mathrm{t}}$ and $z_{t}^{-}$respectively.

The GO-GARCH model of van der Weide (2002) specify the returns $r_{t}$ as a function of the conditional mean $\left(\mathrm{m}_{\mathrm{t}}\right)$ and an error term $\left(\varepsilon_{\mathrm{t}}\right)$ where the conditional mean can include an $\operatorname{AR}(1)$ term.

$$
r_{t}=m_{t}+\varepsilon_{t}
$$

The GO-GARCH model maps $r_{t}-m_{t}$ onto a set of unobservable independent factors $f_{t}$.

$$
\varepsilon_{t}=A f_{t}
$$

The mixing matrix A can be decomposed into an unconditional covariance matrix $\Sigma$ and an orthogonal (rotational) matrix U.

$$
A=\Sigma^{1 / 2} U
$$

In the mixing matrix $A$, the rows are the assets and the columns are the factors (f). The factors can be specified as:

$$
f_{t}=H_{t}^{1 / 2} z_{t}
$$

The random variable $\mathrm{z}_{\mathrm{t}}$ has characteristics $\mathrm{E}\left(\mathrm{z}_{\mathrm{it}}\right)=0$ and $\mathrm{E}\left(\mathrm{z}_{\mathrm{it}}{ }^{2}\right)=1$. The factor conditional variances $h_{i t}$ can be modelled as a GARCH process. The unconditional distribution of factors, f, obey $E\left(f_{t}\right)=0$ and $E\left(f_{t} f_{t}{ }^{\prime}\right)=I$. Combining (11), (12) and (14) yields:

$$
r_{t}=m_{t}+A H_{t}^{1 / 2} z_{t}
$$


The conditional covariance matrix of the returns $\left(\mathrm{r}_{\mathrm{t}}-\mathrm{m}_{\mathrm{t}}\right)$ is:

$$
\Sigma_{t}=A H_{t} A^{\prime}
$$

Two key assumptions of the GO-GARCH model are that 1) A is time invariant, and 2) $\mathrm{H}_{\mathrm{t}}$ is a diagonal matrix. Notice that the OGARCH model is obtained by restricting A to be orthogonal. In the original formation of the GO-GARCH model, van der Weide (2002) used a 1-step maximum likelihood approach to jointly estimate the rotation matrix and the dynamics. This approach, however, is impractical for many assets. The matrix U can also be estimated using nonlinear least squares (van der Weide, 2006) and method of moments (Boswijk and van der Weide, 2011). More recently, it has been proposed that $U$ can be estimated by independent component analysis (ICA) (Broda and Paolella, 2009; Zhang and Chan, 2009) which is the approach taken in this paper ${ }^{3}$.

Asset returns exhibit autocorrelation, volatility clustering and fat tails. This suggests a $\mathrm{AR}(1)$ mean equation for each GARCH model with a multivariate Student $\mathrm{t}$ distribution for the DCC and ADCC models and a Normal Inverse Gaussian (NIG) for the GOGARCH model. The robustness of these specifications is investigated in section 7 of the paper.

\footnotetext{
${ }^{3} \mathrm{U}$ needs to be estimated. For all but a few factors, maximum likelihood is not feasible. For a larger number of factors alternative estimation methods must be used. ICA is a fast statistical technique for estimating hidden factors in relation to observable data.
} 


\section{Data}

This paper uses daily data on emerging market stock prices (EM), oil prices (OIL), the VIX (VIX), gold prices (GOLD), and bond prices (BONDS). Emerging market stock prices are measured by the MSCI Emerging Markets Index priced in US dollars. This is a free float-adjusted market capitalization index that is designed to measure equity market performance of emerging markets. At the time of writing this paper, the index consists of the following 23 emerging market country indices: Brazil, Chile, China, Colombia, Czech Republic, Egypt, Greece, Hungary, India, Indonesia, Korea, Malaysia, Mexico, Peru, Philippines, Poland, Qatar, Russia, South Africa, Taiwan, Thailand, Turkey, and United Arab Emirates ${ }^{4}$.

Oil prices (dollars per barrel) are measured by the continuous contract on the West Texas intermediate crude oil futures contract. Stock market volatility is measured by the VIX. The VIX measures the implied volatility of the S\&P 500 index options and represents the markets expectation of stock market volatility over the next 30 days. Higher values of the VIX represent more uncertainty or "fear" in the market, while lower values of VIX indicate less market uncertainty. Stock prices and oil prices are available from Data Stream International. Gold prices are measured by the Chicago Mercantile Exchange continuous futures contract on gold. Bond prices are measured by the Chicago Mercantile Exchange continuous futures contract on the US 10-year Treasury note. Gold and bond prices are from Quandl while the VIX data are from Yahoo Finance. All prices (except

\footnotetext{
${ }^{4}$ http://www.msci.com/products/indices/tools/index.html\#EM
} 
the VIX which is quoted as a percentage) are in US dollars and the daily data set covers the period January 4, 2000 to July 31, 2014.

We chose to start our estimation sample in 2000 because this year coincides with the beginning of financialization in the commodity markets. After the technology stock market crash of 2000, institutional investors (mutual funds, pension funds, insurance companies, and hedge funds) and wealthy individual investors were looking for new ways to hedge their equity positions. Building on academic research showing a negative correlation between commodities and equities (eg. Greer, 2000; Gorton and Rouwenhorst, 2006; Erb and Harvey, 2006), these investors began investing large amounts of money in commodities. By some estimates, institutional investors increased their purchases of commodity index related financial products from $\$ 15$ billion in 2003 to over $\$ 200$ billion in 2008 (Tang and Xiong, 2009). Furthermore the Commodity Futures Modernization Act of 2000 reduced the cost of futures trading for some groups of investors (eg. mutual funds, insurance companies, banks, and hedge funds). This Act clarified the law by omitting most over-the-counter derivatives being regulated as futures. The Act also specified that in the interest of "financial entrepreneurship" hedge fund activities would be exempt from regulation. Energy derivative trading products were also exempted from regulation.

< Insert Figure 1. Here > 
Time series plots of the raw data are shown in Figure 1. EM and OIL show similar time series patterns with strong trends up to the financial crises of $2008-2009$. Gold displays a strong trend up to 2012. The VIX displays a large spike around the time of the 2008 2009 financial crisis, but little trend. The BONDS series shows a fairly strong trend over the sample period.

For each data series, continuously compounded daily returns are calculated as $100 * \ln \left(\mathrm{p}_{\mathrm{t}} / \mathrm{p}_{\mathrm{t}-1}\right)$ where $\mathrm{p}_{\mathrm{t}}$ is the daily closing or settlement price. The summary statistics for the returns are shown in Table 1. The coefficient of variation indicates that VIX, by a large margin, has the greatest amount of variability while GOLD has the least. EM, OIL, and BONDS have similar variability. The JB test shows that each series is far from normally distributed. The ARCH(12) LM tests indicate strong evidence of ARCH effects. Unit root tests, not reported, indicate that each series of daily returns are stationary.

Table 1. Summary statistics for daily returns

\begin{tabular}{lccccc}
\hline & EM & OIL & VIX & GOLD & BONDS \\
\hline Nobs & 3802 & 3802 & 3802 & 3802 & 3802 \\
min & -9.994 & -16.540 & -35.059 & -15.870 & -2.627 \\
max & 10.073 & 16.410 & 49.601 & 16.320 & 3.537 \\
range & 20.067 & 32.950 & 84.660 & 32.190 & 6.164 \\
median & 0.090 & 0.008 & -0.229 & 0.008 & 0.003 \\
mean & 0.020 & 0.035 & -0.012 & 0.040 & 0.007 \\
SE.mean & 0.020 & 0.038 & 0.101 & 0.022 & 0.007 \\
var & 1.572 & 5.408 & 38.910 & 1.908 & 0.171 \\
std.dev & 1.254 & 2.325 & 6.238 & 1.381 & 0.413 \\
coef.var & 63.044 & 65.680 & -508.997 & 34.830 & 59.130 \\
JB & 10158 & 3939 & 3378 & 115263 & 2767 \\
p-value & $<0.001$ & $<0.001$ & $<0.001$ & $<0.001$ & $<0.001$
\end{tabular}




\begin{tabular}{lccccc} 
ARCH(12) & 1114 & 521.3 & 307.5 & 1044 & 220.9 \\
p-value & $<0.001$ & $<0.001$ & $<0.001$ & $<0.001$ & $<0.001$ \\
\hline
\end{tabular}

Table 2. Pearson correlations between daily returns

\begin{tabular}{lccccc}
\hline & EM & OIL & VIX & GOLD & BONDS \\
\hline EM & 1.000 & $0.261^{\mathrm{a}}$ & $-0.346^{\mathrm{a}}$ & $0.161^{\mathrm{a}}$ & $-0.196^{\mathrm{a}}$ \\
OIL & $0.261^{\mathrm{a}}$ & 1.000 & $-0.150^{\mathrm{a}}$ & $0.215^{\mathrm{a}}$ & $-0.147^{\mathrm{a}}$ \\
VIX & $-0.346^{\mathrm{a}}$ & $-0.150^{\mathrm{a}}$ & 1.000 & $-0.035^{\mathrm{b}}$ & $0.248^{\mathrm{a}}$ \\
GOLD & $0.161^{\mathrm{a}}$ & $0.215^{\mathrm{a}}$ & $-0.035^{\mathrm{b}}$ & 1.000 & $0.095^{\mathrm{a}}$ \\
BONDS & $-0.196^{\mathrm{a}}$ & $-0.147^{\mathrm{a}}$ & $0.248^{\mathrm{a}}$ & $0.095^{\mathrm{a}}$ & 1.000 \\
\hline $\mathrm{p}<0.01^{\mathrm{a}}, \mathrm{p}<0.05^{\mathrm{b}}$ & & & &
\end{tabular}

Unconditional correlations (Table 2) show that EM correlates positively and significantly with OIL and GOLD. EM correlates negatively and significantly with VIX and BONDS. Across all of the asset returns, the strongest correlation is between EM and VIX. Higher volatility (VIX) correlates negatively with emerging market stock returns.

Time series graphs of the squared returns show how volatility has changed across time (Figure 2). Each series displays several periods of volatility clustering. In particular, each series show volatility clustering around the 2008- 2009 financial crisis with the effect being more pronounced for EM and OIL.

< Insert Figure 2. Here > 


\subsection{Empirical results and discussion}

The model building strategy was to first estimate several versions of the DCC model.

Each specification included a constant in the mean equation and a $\operatorname{GARCH}(1,1)$ variance equation. Adjustments were made with respect to including an $\mathrm{AR}(1)$ term in the mean equation and choice of distribution. Model selection criteria indicate that the DCC with and $\mathrm{AR}(1)$ term in the mean equation estimated with a multivariate $\mathrm{t}$ distribution fits best (Table 3). Consequently, all GARCH models (DCC, ADCC, GO-GARCH) are estimated with an $\mathrm{AR}(1)$ term in the mean equation. In order to account for non-normality in the distribution of returns, the DCC and ADCC are estimated with a multivariate $\mathrm{t}$ distribution. The GO-GARCH, for which the multivariate $t$ distribution is not an option, is estimated with a multivariate affine negative inverse Gaussian (MANIG) distribution. How robust the hedge ratios are to these assumptions is further investigated in section 7.

Table 3. Four specifications of the DCC model

\begin{tabular}{|c|c|c|c|c|}
\hline & DCC & DCC & DCC & DCC \\
\hline $\mathrm{AR}(1)$ & yes & no & yes & no \\
\hline Distribution & MVT & MVT & MVNORM & MVNORM \\
\hline AIC & 16.798 & 16.886 & 17.196 & 17.282 \\
\hline $\mathrm{BIC}$ & 16.868 & 16.949 & 17.257 & 17.335 \\
\hline Shibata & 16.797 & 16.886 & 17.196 & 17.282 \\
\hline H-Q & 16.823 & 16.909 & 17.218 & 17.301 \\
\hline LL & -31889 & -32063 & -32653 & -32821 \\
\hline nobs & 3802 & 3802 & 3802 & 3802 \\
\hline
\end{tabular}




\subsection{Regression results}

The DCC and ADCC parameter estimates are presented in Table 4. The estimated coefficient on the $\mathrm{AR}(1)$ term (a) in the mean equation is positive and statistically significant in the EM equation and negative and statistically significant in the VIX and GOLD equations. Short-term persistence is evident in each variable as the estimated coefficient on the $\alpha$ term is statistically significant, and in each case the short-term persistence is less than the long-term persistence ( $\beta$ ). The estimated coefficient on $\beta$ is statistically significant for each variable indicating the importance of long-term persistence. The statistical significance of the $\alpha$ and $\beta$ terms provide evidence of volatility clustering. The estimated asymmetric term $(\gamma)$ is positive and statistically significant for EM and OIL. This indicates that for EM and OIL negative residuals tend to increase the variance (conditional volatility) more than positive shocks of the same magnitude. The estimated asymmetrical term is negative and statistically significant for VIX, GOLD and BONDS indicating that for these series, negative residuals tend to decrease the variance. Different leverage effects may arise from different arbitrage activities, heterogeneity, asymmetric information, or/and contract liquidity.

For the DCC model, the estimated coefficients on $\theta_{1}$ and $\theta_{2}$ are each positive and statistically significant at the $1 \%$ level. These estimated coefficients sum to a value less than one, indicating that the dynamic conditional correlations are mean reverting. In the case of the ADCC model, the dynamic conditional correlations are also mean reverting. 
The Shape parameter $(\lambda)$ is equal to the degrees of freedom. As the number of degrees of freedom approaches infinity, the shape of the $t$ distribution approaches that of a normal. EM and OIL have the highest estimated shaper parameters (over 7) indicating the distributions of the other data series (VIX, GOLD, BONDS) each have heavier tails than the distributions of EM and OIL. Each of the information criteria shows that the ADCC model is the best fitting model $^{5}$.

\footnotetext{
${ }^{5}$ The stability condition $\alpha+(\gamma / 2)+\beta<1$ is satisfied for each GARCH model.
} 
Table 4. DCC and ADCC parameter estimates

\begin{tabular}{lcccccccc}
\hline & DCC & \multicolumn{7}{c}{ ADCC } \\
\hline & Coef. & S.E & $\mathrm{t}$ & prob & Coef. & S.E & $\mathrm{t}$ & prob \\
\hline$\mu_{\mathrm{EM}}$ & 0.0833 & 0.0180 & 4.6164 & 0.0000 & 0.0526 & 0.0188 & 2.7992 & 0.0051 \\
$\mathrm{a}_{\mathrm{EM}}$ & 0.2107 & 0.0162 & 12.9891 & 0.0000 & 0.2161 & 0.0162 & 13.2994 & 0.0000 \\
$\omega_{\mathrm{EM}}$ & 0.0203 & 0.0053 & 3.8479 & 0.0001 & 0.0271 & 0.0065 & 4.1746 & 0.0000 \\
$\alpha_{\mathrm{EM}}$ & 0.0884 & 0.0106 & 8.3387 & 0.0000 & 0.0170 & 0.0075 & 2.2818 & 0.0225 \\
$\beta_{\mathrm{EM}}$ & 0.8966 & 0.0120 & 74.5228 & 0.0000 & 0.8955 & 0.0141 & 63.5625 & 0.0000 \\
$\gamma_{\mathrm{EM}}$ & & & & & 0.1233 & 0.0214 & 5.7685 & 0.0000 \\
$\lambda_{\mathrm{EM}}$ & 8.5997 & 1.0581 & 8.1277 & 0.0000 & 10.3102 & 1.4843 & 6.9463 & 0.0000 \\
$\mu_{\mathrm{OIL}}$ & 0.0685 & 0.0279 & 2.4512 & 0.0142 & 0.0597 & 0.0280 & 2.1285 & 0.0333 \\
$\mathrm{a}_{\mathrm{OIL}}$ & -0.0265 & 0.0164 & -1.6187 & 0.1055 & -0.0267 & 0.0163 & -1.6332 & 0.1024 \\
$\omega_{\mathrm{OIL}}$ & 0.0159 & 0.0064 & 2.4702 & 0.0135 & 0.0160 & 0.0066 & 2.4270 & 0.0152 \\
$\alpha_{\mathrm{OIL}}$ & 0.0406 & 0.0025 & 16.2262 & 0.0000 & 0.0253 & 0.0054 & 4.6714 & 0.0000 \\
$\beta_{\mathrm{OIL}}$ & 0.9567 & 0.0008 & 1200.0284 & 0.0000 & 0.9572 & 0.0008 & 1276.0582 & 0.0000 \\
$\gamma_{\mathrm{OIL}}$ & & & & & 0.0283 & 0.0100 & 2.8314 & 0.0046 \\
$\lambda_{\mathrm{OIL}}$ & 7.4255 & 0.9216 & 8.0569 & 0.0000 & 7.5753 & 0.9537 & 7.9428 & 0.0000 \\
$\mu_{\mathrm{VIX}}$ & -0.2981 & 0.0755 & -3.9480 & 0.0001 & -0.1925 & 0.0774 & -2.4872 & 0.0129 \\
$a_{\mathrm{VIX}}$ & -0.0748 & 0.0161 & -4.6455 & 0.0000 & -0.0712 & 0.0164 & -4.3566 & 0.0000 \\
$\omega_{\mathrm{VIX}}$ & 2.3366 & 0.5559 & 4.2030 & 0.0000 & 2.1284 & 0.5115 & 4.1608 & 0.0000 \\
$\alpha_{\mathrm{VIX}}$ & 0.1066 & 0.0162 & 6.5990 & 0.0000 & 0.1563 & 0.0260 & 6.0154 & 0.0000 \\
$\beta_{\mathrm{VIX}}$ & 0.8372 & 0.0253 & 33.0537 & 0.0000 & 0.8692 & 0.0248 & 35.0119 & 0.0000 \\
$\gamma_{\mathrm{VIX}}$ & & & & & -0.1866 & 0.0286 & -6.5333 & 0.0000 \\
$\lambda_{\mathrm{VIX}}$ & 4.9320 & 0.4051 & 12.1753 & 0.0000 & 5.1281 & 0.4342 & 11.8093 & 0.0000 \\
$\mu_{\mathrm{GOLD}}$ & 0.0600 & 0.0136 & 4.4169 & 0.0000 & 0.0617 & 0.0136 & 4.5368 & 0.0000 \\
$a_{\mathrm{GOLD}}$ & -0.0593 & 0.0143 & -4.1475 & 0.0000 & -0.0583 & 0.0143 & -4.0701 & 0.0000
\end{tabular}




\begin{tabular}{|c|c|c|c|c|c|c|c|c|}
\hline$\omega_{\mathrm{GOLD}}$ & 0.0381 & 0.0273 & 1.3986 & 0.1619 & 0.0359 & 0.0212 & 1.6944 & 0.0902 \\
\hline$\alpha_{\mathrm{GOLD}}$ & 0.0583 & 0.0302 & 1.9311 & 0.0535 & 0.0759 & 0.0312 & 2.4314 & 0.0150 \\
\hline$\beta_{\mathrm{GOLD}}$ & 0.9234 & 0.0418 & 22.0672 & 0.0000 & 0.9243 & 0.0330 & 27.9874 & 0.0000 \\
\hline$\gamma_{\mathrm{GOLD}}$ & & & & & -0.0323 & 0.0176 & -1.8331 & 0.0668 \\
\hline$\lambda_{\mathrm{GOLD}}$ & 3.4309 & 0.2210 & 15.5243 & 0.0000 & 3.4619 & 0.2270 & 15.2523 & 0.0000 \\
\hline$\mu_{\mathrm{BONDS}}$ & 0.0122 & 0.0053 & 2.3115 & 0.0208 & 0.0136 & 0.0053 & 2.5515 & 0.0107 \\
\hline $\mathrm{a}_{\mathrm{BONDS}}$ & -0.0095 & 0.0157 & -0.6070 & 0.5438 & -0.0097 & 0.0157 & -0.6149 & 0.5386 \\
\hline$\omega_{\mathrm{BONDS}}$ & 0.0005 & 0.0002 & 2.6943 & 0.0071 & 0.0005 & 0.0002 & 2.7783 & 0.0055 \\
\hline$\alpha_{\mathrm{BONDS}}$ & 0.0281 & 0.0017 & 16.1610 & 0.0000 & 0.0376 & 0.0050 & 7.5417 & 0.0000 \\
\hline$\beta_{\text {BONDS }}$ & 0.9691 & 0.0004 & 2522.8859 & 0.0000 & 0.9686 & 0.0004 & 2639.2865 & 0.0000 \\
\hline$\gamma_{\text {BONDS }}$ & & & & & -0.0164 & 0.0082 & -2.0048 & 0.0450 \\
\hline$\lambda_{\mathrm{BONDS}}$ & 6.1338 & 0.5804 & 10.5688 & 0.0000 & 6.1570 & 0.5870 & 10.4893 & 0.0000 \\
\hline$\theta_{1}$ & 0.0116 & 0.0023 & 5.1581 & 0.0000 & 0.0119 & 0.0025 & 4.8290 & 0.0000 \\
\hline$\theta_{2}$ & 0.9812 & 0.0047 & 208.5169 & 0.0000 & 0.9801 & 0.0053 & 184.7558 & 0.0000 \\
\hline$\theta_{3}$ & & & & & 0.0013 & 0.0007 & 1.7623 & 0.0780 \\
\hline$\lambda$ & 6.6696 & 0.2816 & 23.6842 & 0.0000 & 6.8689 & 0.2988 & 22.9845 & 0.0000 \\
\hline AIC & 16.798 & & & & 16.774 & & & \\
\hline BIC & 16.868 & & & & 16.855 & & & \\
\hline Shibata & 16.797 & & & & 16.774 & & & \\
\hline H-Q & 16.823 & & & & 16.803 & & & \\
\hline LL & -31889 & & & & -31839 & & & \\
\hline nobs & 3802 & & & & 3802 & & & \\
\hline
\end{tabular}


Table 5. GO-GARCH estimates

The rotation matrix $U$

\begin{tabular}{llllll}
\hline & $\mathrm{U}(1)$ & $\mathrm{U}(2)$ & $\mathrm{U}(3)$ & $\mathrm{U}(4)$ & $\mathrm{U}(5)$ \\
\hline $\mathrm{U}(1)$ & -0.0529 & 0.0333 & -0.0571 & -0.9750 & 0.2055 \\
$\mathrm{U}(2)$ & 0.0266 & -0.9130 & -0.2046 & 0.0527 & 0.3481 \\
$\mathrm{U}(3)$ & -0.1233 & 0.2658 & -0.9407 & 0.1000 & 0.1385 \\
$\mathrm{U}(4)$ & -0.0135 & -0.3028 & -0.2367 & -0.1863 & -0.9041 \\
$\mathrm{U}(5)$ & 0.9905 & 0.0553 & -0.1179 & -0.0436 & 0.0066 \\
\hline
\end{tabular}

The mixing matrix A

\begin{tabular}{lccccc}
\hline & $\mathrm{A}(1)$ & $\mathrm{A}(2)$ & $\mathrm{A}(3)$ & $\mathrm{A}(4)$ & $\mathrm{A}(5)$ \\
\hline $\mathrm{A}(1)$ & 0.0597 & -0.1136 & 0.1254 & 0.2617 & -1.1817 \\
$\mathrm{~A}(2)$ & -0.0634 & 2.1606 & 0.2411 & 0.3435 & -0.7448 \\
$\mathrm{~A}(3)$ & -0.3365 & 0.3494 & -0.3180 & -6.0682 & 1.1373 \\
$\mathrm{~A}(4)$ & 0.1321 & 0.1387 & 1.3475 & -0.0426 & -0.1069 \\
$\mathrm{~A}(5)$ & 0.3884 & -0.0079 & 0.0052 & -0.1112 & 0.0841 \\
\hline
\end{tabular}

GO-GARCH parameter estimates

\begin{tabular}{lccccc}
\hline & F1 & F2 & F3 & F4 & F5 \\
\hline$\omega$ & 0.0037 & 0.0031 & 0.0180 & 0.0655 & 0.0144 \\
$\alpha$ & 0.0296 & 0.0402 & 0.0462 & 0.1016 & 0.0782 \\
$\beta$ & 0.9665 & 0.9567 & 0.9312 & 0.8330 & 0.9044 \\
skew & -0.1921 & -0.0282 & -0.0437 & -0.2736 & 0.1495 \\
shape & 1.6645 & 2.0784 & 0.5911 & 1.5919 & 3.0648 \\
\hline LL & -31930.83 & & & & \\
\hline
\end{tabular}

For the GO-GARCH model it is usual to present the rotation matrix (U), the mixing matrix (A), and the parameter estimates (Table 5). The rotation matrix $\mathrm{U}$ is orthogonal because $\mathrm{U}^{\mathrm{T}} \mathrm{U}=\mathrm{I}$. Notice that since the GO-GARCH estimates factors, no standard errors are estimated. For each factor the estimated short-run persistence $(\alpha)$ is considerably less 
than the long-run persistence $(\beta)$ which is consistent with the findings from the DCC and ADCC models. The fourth factor displays more short term variation and less long term variation.

\subsection{Dynamic conditional correlations}

One-step-ahead dynamic conditional correlations are constructed using a rolling window analysis. The estimation window is fixed at 2802 observations and 1000 one-step-ahead dynamic conditional correlations are produced. GARCH models are refit every 20 observations. Section 7 presents robustness results for forecast length, number of model refits, and distributional assumptions. For the case of EM and OIL the one-step-ahead dynamic conditional correlations between the DCC and ADCC models are very similar (Figure 3). These correlations have been trending downwards since late 2011. In comparison, the correlations estimated from the GO-GARCH model show a different pattern. All three correlations rose in late 2011, but while the correlations from the DCC type models gradually weakened the correlations from the GO-GARCH model have remained fairly strong.

The dynamic conditional correlations between EM and VIX are negative for each of the GARCH models, suggesting significant diversification benefits. Intuitively, the inverse relationship between equity and volatility means that equity markets tend to lose money when volatility or uncertainty increases. This is often attributed to Black's leverage effect, although the effect is generally asymmetric (Yu 2005). The correlations between 
the DCC and ADCC models are very similar and show periods of reduced correlation in early 2013 and 2014. The correlations from the GO-GARCH model, however, show much less variability.

The dynamic conditional correlations between EM and GOLD are positive for each estimation model. Generally gold has a positive correlation to emerging-market growth due to countries like China, India and the entire Southeast Asia region's cultural affinity to gold. In fact, over the past decade, over half of global consumer demand for gold originated from China and India. Furthermore, between 2001 and 2012, the correlation between gold and emerging market equities in US dollar terms was 0.28 , compared to a much smaller 0.11 correlation to developed-market equities (World Gold Council 2013). Correlations from the DCC and ADCC models show more variability than those from the GO-GARCH model.

The dynamic conditional correlations between EM and BONDS fluctuate between negative and positive values. The negative EM/BONDS correlation is likely a result of the so-called "Bernanke put", which resulted in a practically zero short-term interest rate (and hence a lower yield on the 10-year Treasury bonds) and a sustained equity bubble in both developed and emerging markets. Whereas, the positive EM/BONDS correlation may reflect investors' risk-on/off trading approach to asset allocation (i.e., flight to quality) as a result of Fed's planned tapering of its quantitative easing policy that sparked a sell-off in emerging market equities. Unlike the correlations between EM/OIL, EM/VIX or EM/GOLD the EM/BONDS correlations produced from the three models

\footnotetext{
${ }^{6}$ Cassidy (2013).
} 
track each other fairly closely. Throughout 2012 and the first part of 2013, the correlation between EM and BONDS was negative before spiking to a positive value midway through 2013.

< Insert Figure 3. Here >

For each pair of correlations, the dynamic conditional correlations produced from the DCC model correlate very high with those produced from the ADCC model (Table 6). For each pair of correlations, the correlations between DCC and GO-GARCH (or ADCC and GO-GARCH) are considerably less which is consistent with Figure 3. One way to further investigate these differences is to look at news impact correlation surfaces. The lowest correlation between DCC and GO-GARCH occurs for EM/VIX. The DCC news impact correlation surface between EM and VIX shows an interesting shape (Figure 4a). Along the $\mathrm{z} \_1$ axis (EM) the correlation surfaces between EM and VIX traces out a positive to a negative pattern. By comparison, along the $z \_2$ axis (VIX) the correlation surfaces traces out a negative to positive relationship. In either case, shocks to EM or VIX have asymmetric effects on the correlation between these two assets. The ADCC news impact correlation surface between EM and VIX shows a very similar shape to that from the DCC (Figure 4b). The GO-GARCH news impact correlation surface between EM and VIX (Figure 4c) shows a very different shape than the corresponding one from the DCC or ADCC. In the case of the GO-GARCH, the news impact correlation surface is concave whereas the news impact correlation surface for the DCC and ADCC are more convex. Moreover, the GO-GARCH news impact correlation surface displays more 
symmetry than either of the DCC or $\mathrm{ADCC}^{7}$. This is expected since the GO-GARCH factors are orthogonalized. Also notice that the correlations between EM and VIX are all negative in the case of the GO-GARCH. Recall, however, that for the GO-GARCH, the shocks pertain to factors. The DCC and ADCC news impact correlation surfaces are very similar to each other but very different from the GO-GARCH.

Table 6. Correlations between correlations

\begin{tabular}{lcccc}
\hline & EM/OIL & EM/VIX & EM/GOLD & EM/BONDS \\
\hline DCC/ADCC & 0.9980 & 0.9952 & 0.9980 & 0.9982 \\
DCC/GO-GARCH & 0.6260 & 0.0612 & 0.2179 & 0.3227 \\
ADCC/GO-GARCH & 0.6210 & 0.0750 & 0.2156 & 0.3306 \\
\hline
\end{tabular}

$<$ Insert Figure 4. Here >

\section{Hedging}

The return on a portfolio of a spot and futures position can be represented as:

$$
R_{H, t}=R_{S, t}-\gamma_{t} R_{F, t}
$$

Where $\mathrm{R}_{\mathrm{H}, \mathrm{t}}$ is the return on the hedged portfolio, $\mathrm{R}_{\mathrm{S}, \mathrm{t}}$ are the returns on the spot position, $\mathrm{R}_{\mathrm{F}, \mathrm{t}}$ are the returns on the futures position and $\gamma_{\mathrm{t}}$ is the hedge ratio. If the investor is long in the spot position then the hedge ratio is the number of futures contracts that must be

\footnotetext{
${ }^{7}$ This pattern is also observed between EM and each of the other assets.
} 
sold. The variance of the hedged portfolio conditional on the information set at time $\mathrm{t}-1$ is:

$$
\begin{gathered}
\operatorname{var}\left(R_{H, t} \mid I_{t-1}\right)=\operatorname{var}\left(R_{S, t} \mid I_{t-1}\right) \\
-2 \gamma_{t} \operatorname{cov}\left(R_{F, t}, R_{S, t} \mid I_{t-1}\right)+\gamma_{t}^{2} \operatorname{var}\left(R_{F, t} \mid I_{t-1}\right)
\end{gathered}
$$

The optimal hedge ratios (OHRs) are the $\gamma_{\mathrm{t}}$ which minimize the conditional variance of the hedged portfolio. The optimal hedge ratio conditional on the information set $\mathrm{I}_{\mathrm{t}-1}$ can be obtained by taking the partial derivative of the variance with respect to $\gamma_{\mathrm{t}}$ and setting the expression equal to zero (Baillie and Myers, 1991).

$$
\gamma_{t}^{*} I_{t-1}=\frac{\operatorname{cov}\left(R_{S, t}, R_{F, t} \mid I_{t-1}\right)}{\operatorname{var}\left(R_{F, t} \mid I_{t-1}\right)}
$$

The conditional volatility estimates from GARCH models can be used to construct hedge ratios (Kroner and Sultan, 1993). A long position in one asset (say asset i) can be hedged with a short position in a second asset (say asset $\mathrm{j}$ ). The hedge ratio between spot and futures prices is

$$
\gamma_{t}^{*} \mid I_{t-1}=h_{S F t} / h_{F t}
$$

Where $h_{\mathrm{SF}, \mathrm{t}}$ is the conditional covariance between spot and futures returns and $\mathrm{h}_{\mathrm{F}, \mathrm{t}}$ is the conditional variance of futures returns.

The performance of different OHRs obtained from different GARCH models is measured using the hedging effectiveness (HE) index (eg. Chang et al., 2011, Ku et al, 2007). 


$$
H E=\frac{\text { var }_{\text {unhedged }}-\text { var }_{\text {hedged }}}{\text { var }_{\text {unhedged }}}
$$

A higher HE index indicates a higher hedging effectiveness.

Out-of-sample hedge ratios are constructed using a rolling window analysis. At time period t, a one-period-ahead conditional volatility forecast is made and these forecasts are used to construct a one-period-ahead hedge ratio. These forecasted hedge ratios are then used in constructing the hedged portfolio. A rolling window size of 2802 observations is used to construct 1000 one-period-ahead hedge ratios.

Figure 5 shows optimal hedge ratios computed between EM and a position in either OIL, VIX, GOLD, or BONDS. Notice that the GO-GARCH hedge ratios have less variability than either the DCC or ADCC hedge ratios. Also notice that the DCC hedge ratios are very similar to the ADCC hedge ratios. All hedge ratios experienced large drops in the second half of 2011 due likely to the European Debt Crisis and Standard \& Poor's downgrade of America's credit rating from AAA to AA+.

$<$ Insert Figure 5. Here >

Correlations between the hedge ratios computed from different GARCH models shows that the hedge ratios computed from the DCC and ADCC correlate very highly (Table 7). The correlations between the DCC and GO-GARCH hedge ratios are considerably lower as are the correlations between the ADCC and GO-GARCH hedge ratios. 
Table 7. Correlations between hedge ratios

\begin{tabular}{lcccc}
\hline & EM/OIL & EM/VIX & EM/GOLD & EM/BONDS \\
\hline DCC/ADCC & 0.9724 & 0.9634 & 0.9525 & 0.9853 \\
DCC/GO-GARCH & 0.6681 & 0.8920 & 0.3557 & 0.8649 \\
ADCC/GO-GARCH & 0.6608 & 0.8367 & 0.2711 & 0.8464 \\
\hline
\end{tabular}

Notes: Forecasts calculated from fixed width rolling analysis which produces 1000 onestep forecasts. Models are refit every 20 observations. DCC and ADCC estimated using a multivariate $\mathrm{t}$ (MVT) distribution. GO-GARCH estimated using a multivariate affine negative inverse Gaussian (MANIG) distribution. All specifications include a constant and an $\mathrm{AR}(1)$ term in the mean equation.

The average value of the hedge ratio between EM and OIL is 19 cents for the DCC model indicating that a $\$ 1$ long position in EM can be hedged for 19 cents in the oil market (Table 8, middle panel). By comparison, the average value of the EM/OIL hedge ratio is 19 cents when computed using the ADCC model and 22 cents when using the GO-

GARCH model. The ADCC model provides the highest hedging effectiveness while the GO-GARCH model is least effective.

The average value of the EM/GOLD hedge ratio is 18 cents for the DCC model, 19 cents for the ADCC model, and 14 cents for the GO-GARCH model. The GO-GARCH produces the most effective hedge while DCC produces the least effective. One possible reason for this is that the fourth factor in the GO-GARCH has higher short term persistence and lower long-term persistence which is better suited to capture the dynamics in this hedge. 
For the EM/VIX and EM/BONDS hedges, the average values of the hedge ratios are negative. This occurs because these pairs are negatively correlated. The hedge is formed by either being long on both assets or being short on both assets. The ADCC model produces the most effective hedge for EM/VIX and for EM/BONDS. Notice that out of the four hedges constructed, the ADCC model produces the most effective hedges in three of the cases.

These findings have important implications for investors seeking higher yields from emerging market equities while hedging their tail risk within portfolio construction. Overall, the hedging effectiveness is highest for the EM/OIL hedge indicating that OIL is a more desirable hedge for EM than VIX, GOLD, or BONDS. VIX provides the second highest hedging effectiveness indicating the usefulness of a volatility index in hedging emerging market stock prices. GOLD provides the third highest hedging effectiveness. With emerging-market investments gold is considered to provide efficient tail-risk hedge due to its lower overlay costs and for its little correlation with many asset classes (particularly the US dollar) ${ }^{8}$; our results add to this knowledge by showing the fraction of a \$1 long position in emerging market equities can be hedged by incorporating gold in the hedging strategy. In addition, the dynamic correlation between EM and BONDS provides a stark reminder of the global implications of the U.S. monetary policy, especially the challenges they create for investors in emerging markets.

\footnotetext{
${ }^{8}$ World Gold Council (2013).
} 


\section{Robustness analysis}

The hedging effectiveness values discussed in the previous section were obtained under specific assumptions about forecast horizon, the number of model refits, and the choice of distribution. This section of the paper presents some results on robustness. Table 8 provides some additional information on how robust the hedging effectiveness values are to changes in the number of model refits. Results are presented showing hedging effectiveness values estimated from models refit every 10 days, 20 days, and 60 days. For each hedge and GARCH model specification, the hedging effectiveness values are fairly similar across different model refits. For example, in the case of the EM/OIL hedge, the ADCC produces hedging effectiveness values of $0.1889,0.1887$, and 0.1883 for the refits 10,20 and 60 respectively. In the case of the EM/GOLD hedge, the GO-GARCH produces the highest hedging effectiveness for refits 10, 20, 60 days indicating that the hedging results are robust to the choice of number of model refits.

Table 9 provides some results showing hedging effectiveness values estimated with a normal distribution and no $\mathrm{AR}(1)$ term in the mean equation. For the EM/OIL hedge, the ADCC produces the largest HE for each of the three refit choices. This is also the case for the EM/VIX and EM/BONDS hedge ratios. For the EM/GOLD hedge, the GO-GARCH is preferred for refits of 10 and 60. Oil provides the most effective hedge for emerging market stock prices.

Table 10 presents results on how robust the hedge ratios are to the choice of different forecast lengths. Here the GARCH models are estimated with a non-normal distribution. 
Notice that for forecast lengths of 500 days, some of the HE values are negative indicating the hedged portfolio performs worse than the unhedged portfolio. This could occur because the fixed estimation window in the rolling window analysis is too large to adequately account for large changes in the data. For the EM/OIL hedge, ADCC is preferred (largest HE value) across all forecast horizons. For the EM/VIX hedge, the ADCC is preferred for forecast lengths of 500 and 1000. For longer forecast lengths, the DCC is preferred. For the EM/GOLD hedge, the GO-GARCH is preferred for forecast lengths of 500 and 1000. Forecast lengths of 500 and 1000 days correspond to starting dates of August 31, 2012 and October 1, 2010. Both of these starting dates occurred after the 2008-2009 recession. Forecast lengths of 1500 and 2000 correspond to starting dates of October 31, 2008 and December 1, 2006. These dates occurred either during or before the 2008-2009 recession. The GO-GARCH seems to not capture the volatile nature of asset prices during the 2008-2009 recession as well as the DCC and ADCC models. For longer forecast lengths, the ADCC is preferred. For the EM/BONDS hedge, ADCC is preferred. 
Table 8. Hedge ratio summary statistics and hedging effectiveness (HE)

\begin{tabular}{|c|c|c|c|c|c|c|c|c|c|c|c|c|}
\hline & \multicolumn{4}{|l|}{ r.e $=10$} & \multicolumn{4}{|l|}{ r.e $=20$} & \multicolumn{4}{|l|}{ r.e $=60$} \\
\hline & mean & $\min$ & $\max$ & $\mathrm{HE}$ & mean & $\min$ & $\max$ & $\mathrm{HE}$ & mean & $\min$ & $\max$ & $\mathrm{HE}$ \\
\hline \multicolumn{13}{|l|}{ EM/OIL } \\
\hline DCC & 0.1869 & 0.0282 & 0.5598 & 0.1816 & 0.1867 & 0.0303 & 0.5523 & 0.1814 & 0.1857 & 0.0316 & 0.5523 & 0.1811 \\
\hline ADCC & 0.1859 & 0.0182 & 0.5964 & 0.1889 & 0.1857 & 0.0201 & 0.5898 & 0.1887 & 0.1846 & 0.0256 & 0.5898 & 0.1883 \\
\hline GO-GARCH & 0.2176 & 0.0261 & 0.6711 & 0.1652 & 0.2171 & 0.0270 & 0.6676 & 0.1652 & 0.2146 & 0.0264 & 0.6675 & 0.1652 \\
\hline \multicolumn{13}{|l|}{ EM/VIX } \\
\hline DCC & -0.0614 & -0.1999 & -0.0125 & 0.1463 & -0.0614 & -0.1989 & -0.0128 & 0.1463 & -0.0615 & -0.1989 & -0.0130 & 0.1464 \\
\hline$A D C C$ & -0.0593 & -0.1746 & -0.0117 & 0.1515 & -0.0593 & -0.1742 & -0.0119 & 0.1516 & -0.0593 & -0.1742 & -0.0121 & 0.1516 \\
\hline GO-GARCH & -0.0682 & -0.1644 & -0.0426 & 0.1359 & -0.0682 & -0.1647 & -0.0431 & 0.1356 & -0.0684 & -0.1647 & -0.0433 & 0.1354 \\
\hline \multicolumn{13}{|l|}{ EM/GOLD } \\
\hline DCC & 0.1772 & -0.0864 & 0.3952 & 0.0525 & 0.1773 & -0.0762 & 0.3969 & 0.0529 & 0.1771 & -0.0722 & 0.3914 & 0.0523 \\
\hline$A D C C$ & 0.1929 & -0.0705 & 0.5202 & 0.0563 & 0.1930 & -0.0576 & 0.5202 & 0.0565 & 0.1930 & -0.0513 & 0.5202 & 0.0557 \\
\hline GO-GARCH & 0.1397 & 0.0678 & 0.2111 & 0.0575 & 0.1396 & 0.0693 & 0.2109 & 0.0575 & 0.1385 & 0.0678 & 0.2091 & 0.0564 \\
\hline \multicolumn{13}{|l|}{ EM/BONDS } \\
\hline DCC & -0.5559 & -1.9180 & 0.7778 & 0.0658 & -0.5557 & -1.8960 & 0.7487 & 0.0657 & -0.5541 & -1.8960 & 0.7342 & 0.0652 \\
\hline$A D C C$ & -0.5148 & -2.0480 & 1.1085 & 0.0676 & -0.5140 & -2.0250 & 1.1020 & 0.0675 & -0.5126 & -2.0250 & 1.0879 & 0.0669 \\
\hline GO-GARCH & -0.7082 & -2.7390 & 0.0816 & 0.0440 & -0.7092 & -2.7220 & 0.0934 & 0.0433 & -0.7073 & -2.7270 & 0.1123 & 0.0426 \\
\hline
\end{tabular}

Notes: Hedge ratios calculated from fixed width rolling analysis which produces 1000 one-step forecasts. Models are refit every 10, 20 or 60 observations. DCC and ADCC estimated using a multivariate t (MVT) distribution. GO-GARCH estimated using a multivariate affine negative inverse Gaussian (MANIG) distribution. All specifications include a constant and an AR(1) term in the mean equation. 
Table 9. Hedge ratio summary statistics and hedging effectiveness (HE) - MVN distribution

\begin{tabular}{|c|c|c|c|c|c|c|c|c|c|c|c|c|}
\hline & $\begin{array}{c}r . e=10 \\
\text { mean }\end{array}$ & $\min$ & $\max$ & $\mathrm{HE}$ & $\begin{array}{c}r . e=20 \\
\text { mean }\end{array}$ & $\min$ & $\max$ & $\mathrm{HE}$ & $\begin{array}{c}r . e=60 \\
\text { mean }\end{array}$ & $\min$ & $\max$ & $\mathrm{HE}$ \\
\hline \multicolumn{13}{|l|}{ EM/OIL } \\
\hline DCC & 0.1855 & 0.0357 & 0.5399 & 0.1799 & 0.1854 & 0.0410 & 0.5322 & 0.1800 & 0.1842 & 0.0391 & 0.5322 & 0.1788 \\
\hline \multicolumn{12}{|l|}{ EM/VIX } & 0.1650 \\
\hline DCC & -0.0576 & -0.1970 & -0.0118 & 0.1456 & -0.0576 & -0.1954 & -0.0121 & 0.1457 & -0.0576 & -0.1954 & -0.0123 & 0.1461 \\
\hline \multicolumn{12}{|l|}{ EM/GOLD } & 0.1411 \\
\hline DCC & 0.1753 & -0.1234 & 0.3964 & 0.0471 & 0.1755 & -0.0954 & 0.3964 & 0.0478 & 0.1759 & -0.0801 & 0.3964 & 0.0467 \\
\hline ADCC & 0.1927 & -0.0976 & 0.6064 & 0.0525 & 0.1931 & -0.0747 & 0.6064 & 0.0530 & 0.1947 & -0.0714 & 0.6064 & 0.0497 \\
\hline $\begin{array}{l}\text { GO-GARCH } \\
\text { EM/BONDS }\end{array}$ & \multicolumn{11}{|c|}{ EM/BONDS } & 0.0516 \\
\hline
\end{tabular}

Notes: Hedge ratios calculated from fixed width rolling analysis which produces 1000 one-step forecasts. Models are refit every 10,

20 or 60 observations. DCC, ADCC, and GO-GARCH estimated using a multivariate normal (MVN) distribution. All specifications include a constant in the mean equation. 
Table 10. Hedge ratio summary statistics and hedging effectiveness (HE) - different forecast lengths

\begin{tabular}{|c|c|c|c|c|c|c|c|c|c|c|c|c|c|c|c|c|}
\hline & \multicolumn{2}{|c|}{ f.I. $=500$} & \multirow[b]{2}{*}{$\max$} & \multirow[b]{2}{*}{$\mathrm{HE}$} & \multicolumn{3}{|c|}{ f.I. $=1000$} & \multirow[b]{2}{*}{$\mathrm{HE}$} & \multicolumn{2}{|c|}{ f.I. $=1500$} & \multirow[b]{2}{*}{$\max$} & \multirow[b]{2}{*}{ HE } & \multicolumn{2}{|c|}{ f.l. $=2000$} & \multirow[b]{2}{*}{$\max$} & \multirow[b]{2}{*}{$\mathrm{HE}$} \\
\hline & mean & $\min$ & & & mean & $\min$ & $\max$ & & mean & $\min$ & & & mean & $\min$ & & \\
\hline \multicolumn{17}{|l|}{ EM/OIL } \\
\hline DCC & 0.141 & 0.029 & 0.376 & 0.008 & 0.187 & 0.030 & 0.552 & 0.181 & 0.203 & 0.029 & 0.596 & 0.201 & 0.190 & 0.028 & 0.626 & 0.174 \\
\hline$A D C C$ & 0.143 & 0.032 & 0.451 & 0.009 & 0.186 & 0.020 & 0.590 & 0.189 & 0.200 & 0.032 & 0.633 & 0.207 & 0.190 & 0.027 & 0.675 & 0.183 \\
\hline GO-GARCH & 0.217 & 0.070 & 0.423 & -0.022 & 0.217 & 0.027 & 0.668 & 0.165 & 0.216 & -0.021 & 0.690 & 0.176 & 0.191 & -0.020 & 0.706 & 0.149 \\
\hline \multicolumn{17}{|l|}{ EM/VIX } \\
\hline DCC & -0.046 & -0.112 & -0.013 & 0.061 & -0.061 & -0.199 & -0.013 & 0.146 & -0.074 & -0.214 & -0.014 & 0.170 & -0.073 & -0.214 & -0.013 & 0.192 \\
\hline $\mathrm{ADCC}$ & -0.045 & -0.098 & -0.012 & 0.067 & -0.059 & -0.174 & -0.012 & 0.152 & -0.069 & -0.192 & -0.013 & 0.168 & -0.067 & -0.187 & -0.012 & 0.186 \\
\hline GO-GARCH & -0.063 & -0.101 & -0.042 & 0.010 & -0.068 & -0.165 & -0.043 & 0.136 & -0.084 & -0.284 & -0.042 & 0.162 & -0.076 & -0.285 & -0.043 & 0.147 \\
\hline \multicolumn{17}{|l|}{ EM/GOLD } \\
\hline DCC & 0.144 & 0.006 & 0.360 & 0.024 & 0.177 & -0.076 & 0.397 & 0.053 & 0.190 & -0.085 & 0.500 & 0.052 & 0.176 & -0.056 & 0.521 & 0.034 \\
\hline$A D C C$ & 0.155 & 0.013 & 0.388 & 0.018 & 0.193 & -0.058 & 0.520 & 0.057 & 0.202 & -0.076 & 0.547 & 0.053 & 0.186 & -0.040 & 0.599 & 0.034 \\
\hline GO-GARCH & 0.129 & 0.052 & 0.191 & 0.035 & 0.140 & 0.069 & 0.211 & 0.058 & 0.152 & 0.071 & 0.296 & 0.049 & 0.176 & 0.022 & 1.399 & 0.027 \\
\hline \multicolumn{17}{|l|}{ EM/BONDS } \\
\hline DCC & -0.362 & -1.332 & 0.566 & -0.011 & -0.556 & -1.896 & 0.749 & 0.066 & -0.641 & -2.047 & 0.757 & 0.063 & -0.665 & -2.126 & 0.853 & 0.068 \\
\hline ADCC & -0.335 & -1.013 & 0.854 & -0.007 & -0.514 & -2.025 & 1.102 & 0.067 & -0.580 & -2.220 & 1.249 & 0.069 & -0.603 & -2.416 & 1.335 & 0.069 \\
\hline GO-GARCH & -0.598 & -1.781 & -0.024 & -0.075 & -0.709 & -2.722 & 0.093 & 0.043 & -0.708 & -2.876 & 0.147 & 0.038 & -0.676 & -3.073 & 0.202 & 0.060 \\
\hline
\end{tabular}

Notes: Hedge ratios calculated from fixed width rolling analysis which produces f.l. one-step forecasts. Models are refit every 20 observations. DCC and ADCC estimated using a multivariate t (MVT) distribution. GO-GARCH estimated using a multivariate affine negative inverse Gaussian (MANIG) distribution. All specifications include a constant and an AR(1) term in the mean equation. Forecast lengths of 500, 1000, 1500, and 2000 correspond to starting dates of August 31, 2012, October 1, 2010, October 31, 2008, and December 1, 2006 respectively. 


\section{Conclusions}

Estimating GARCH models on large data sets is challenging because of "The curse of dimensionality" (which refers to the tradeoff between generality and feasibility). For some multivariate GARCH specifications, like BEKK, the number of free parameters grows very rapidly as the number of variables increases making estimation infeasible for large data sets. Multivariate GARCH models like CCC, DCC and GO-GARCH offer analytically tractable ways to estimate multivariate GARCH models on large data sets. While CCC and DCC type multivariate GARCH models are very popular, GO-GARCH has seen less use in practice. DCC captures 1) persistence in volatility and correlation and 2) time-varying correlation, but does not capture spill-over effects in volatility nor is DCC closed under linear transformation. GO-GARCH satisfies all four of these requirements but has, until recently, been more difficult to estimate. The purpose of this paper is to estimate DCC, ADCC and GO-GARCH models on a large data set consisting of emerging market stock returns, oil prices, gold prices, bond prices and the VIX and compare the hedge ratios from the different models. The approach taken is to estimate the DCC, ADCC and GO-GARCH models using a fixed rolling window and to estimate onestep-ahead hedge ratios. Models are compared based on their hedging effectiveness.

The one-step-ahead dynamic conditional correlations computed from DCC and ADCC models are very similar. In comparison, the dynamic conditional correlations computed from a GO-GARCH model exhibit less variability compared to either DCC or ADCC. This is particularly evident for the EM/GOLD GO-GARCH dynamic conditional 
correlations which display considerably less variability than the dynamic conditional correlations produced from either DCC or ADCC. This indicates that the GO-GARCH model estimates different conditional correlations and hedge ratios.

The results of this paper have implications for investors. First, emerging market stock prices and oil prices each display positive leverage effects. Negative residuals tend to increase the variance (conditional volatility) more than positive ones. Second, hedge ratios vary considerably over the sample period indicating that hedged positions should be updated regularly. Third of the hedging assets considered, oil is the best hedge for emerging market stock prices because the EM/OIL hedge has the highest hedging effectiveness in most cases. Moreover, for the EM/OIL hedge the ADCC is preferred in most cases. This result is robust to the number of model fits, forecast length, and distribution assumption. Similarly, the ADCC hedge is preferred for the EM/VIX and EM/BONDS hedges. One possible explanation for why hedge ratios vary between different multivariate GARCH specifications is that different GARCH specifications capture different data properties. The ADCC, for example, captures asymmetric effects, while the DCC and GO-GARCH do not. This is an important distinction, because EM and OIL display positive and significant asymmetry coefficients while VIX, GOLD and BONDS each display negative and significant asymmetry coefficients. Fourth, the GOGARCH is preferred for hedging EM/GOLD over forecast lengths of 500 or 1000 days. This result is reasonably robust to number of model fits and distributional assumptions. One possible explanation for the better hedging effectiveness performance of the GOGARCH for the EM/GOLD hedge is that the fourth factor has more short term 
persistence and less long term persistence which provides a closer fit to the dynamics of GOLD price volatility. In general, GO-GARCH performs better, in terms of hedging effectiveness, after the 2008-2009 recession.

The main take-away from our research is that oil provides the most effective hedge for emerging market stock prices under most of the situations we considered. For each hedge, the ADCC produces better hedging effectiveness in most cases but not in all cases. The GO-GARCH can, in some cases pertaining to the EM/GOLD hedge, provide better hedging effectiveness. Rather than relying on one GARCH model to produce all the hedge ratios, our recommendation is to consider several GARCH models. In order to achieve higher hedging effectiveness it is desirable to consider different GARCH models for different hedges. 


\section{References}

Alexander, C. 2001. "Orthogonal GARCH”, Chapter 2 (pp. 21-38) in C. Alexander (Ed.), Mastering Risk. London: Financial Times-Prentice Hall.

Arouri, M. Jouini, J. Nguyen, D.K 2011a. Volatility spillovers between oil prices and stock sector returns: Implications for portfolio management. Journal of International Money and Finance 30, 1387-1405.

Arouri, M. Lahiani, A. Nguyen, D.K. 2011b. Return and volatility transmission between world oil prices and stock markets of the GCC countries. Economic Modelling 28, 18151825.

Arouri, M. Jouini, J. Nguyen, D.K. 2012. On the impacts of oil price fluctuations on European equity markets : Volatility spillover and hedging effectiveness, Energy Economics 34, 611-617.

Baba, Y., Engle, R.F., Kraft, D., Kroner, K.F. 1990. Multivariate simultaneous generalized ARCH. Mimeo, Department of Economics, University of California, San Diego

Baillie, R.T., Myers,R.J. 1991. Bivariate GARCH estimation of the optimal commodity futures hedge. Journal of Applied Econometrics 6, 109-124.

Bauwens, L., S. Laurent, Rombouts, J. V. K. 2006. Multivariate GARCH models: A survey. Journal of Applied Econometrics 21, 79-109.

Beckmann,J., Czudaj,R. 2014. Volatility transmission in agricultural futures markets. Economic Modelling 36, 541-546.

Boswijk, P.H. , van der Weide, R.. 2011. Method of moments estimation of go-garch models. Journal of Econometrics, 163(1):118-126.

Broda, S.A., Paolella, M.S. 2009. Chicago: A fast and accurate method for portfolio risk calculation. Journal of Financial Econometrics, 7(4):412-436.

Cappiello,L., Engle, R.F., Sheppard, K. 2006. Asymmetric correlations in the dynamics of global equity and bond returns. Journal of Financial Econometrics, 4(4):537-572.

Cassidy, J., 2013, The Bernanke put: can the markets and the economy live without it? The New Yorker, June 21.

Chang, C-Y, Lai, J-L, Chuang, I-Y, 2010. Futures heging effectiveness under the segmentaion of bull/bull energy markets. Energy Economics 32, 442-449.

Chang, C.-L., M. McAleer, Tansuchat, R. 2011.Crude oil hedging strategies using dynamic multivariate GARCH. Energy Economics 33, 912-923. 
Chang, C.-L., M. McAleer, Tansuchat, R. 2013. Conditional correlations and volatility spillovers between crude oil and stock index returns. North American Journal of Economics and Finance 25, 116-138.

Caporin, M., McAleer, M., 2012. Do we really need both BEKK and DCC? A tale of two multivariate GARCH models, Journal of Economic Surveys 26 (4), 736-751.

Choi, K., Hammoudeh, S., 2010. Volatility behavior of oil, industrial commodity and stock markets in a regime-switching environment. Energy Policy 38, 4388-4399.

Creti, A., Joets, M., Mignon, V. 2013. On the link between stock and commodity markets' volatility. Energy Economics 37, 16-28.

Ding, Z. 1994. Time Series Analysis of Speculative Returns. PhD Dissertation, University of California at San Diego.

Domanski, D., Heath, A., 2007. Financial investors and commodity markets. BIS Quarterly Review, 53-67.

Dwyer, A., Gardner, G., Williams, T., 2011. Global commodity markets-price volatility and financialisation. Reserve Bank of Australia Bulletin, June, 49-57.

Du, X., Yu, C.L., Hayes, D.J., 2011. Speculation and volatility spillover in the crude oil and agricultural commodity markets: A Bayesian analysis. Energy Economics 33, 497-503.

Engle, R.F. 2002. Dynamic conditional correlation: A simple class of multivariate generalized autoregressive conditional heteroskedasticity models. Journal of Business and Economic Statistics 20, 339-350.

R.F. Engle, V. Ng, ,M. Rothschild, 1990. Asset pricing with a factor arch covariance structure: Empirical estimates for treasury bills. Journal of Econometrics, 45:213-237.

Erb, C.B., Harvey, C.R., 2006. The strategic and tactical value of commodity futures. Financial Analyst Journal 62, 69-97.

Fayyad, A., Daly, K., 2011. The impact of oil price shocks on stock market returns: comparing GCC countries with the UK and USA. Emerg. Mark. Rev. 12, 61-78

Filis, G., Degiannakis, S., Floros, C., 2011. Dynamic correlation between stockmarket and oil prices: the case of oil-importing and oil-exporting countries. Int. Rev. Financ. Anal. 20, 152-164.

Ghalanos, A., Rossi, E., Urga, G. 2012. Independent factor autoregressive conditional density model. DEM Working Paper Series No. 21 (11-12), Universita Di Pavia.

Ghalanos, A. 2014. rmgarch: Multivariate GARCH models. R package version 1.2-8. 
Glosten, L.R., Jagannathan, R., Runkle. D.E. 1993. On the relation between the expected value and the volatility of the nominal excess return on stocks. Journal of Finance 48, 1779-1801.

Greer, R. 2000. The nature of commodity index returns. Journal of Alternative Investments 3, 45-52.

Guesmi, K., Fattoum, S. 2014. Return and volatility transmission between oil prices and oil-exporting and oil-importing countries. Economic Modelling, 38, 305-310

Hakim, A., McAleer, M. 2010. Modelling the interactions across international stock, bond and foreign exchange markets. Applied Economics 42, 825-850.

Hammoudeh, S. Yuan, Y. 2008. Metal volatility in presence of oil and interest rate shocks. Energy Economics 30, 606-620.

Hammoudeh, S., Malik, F. McAleer, M. 2011. Risk management of precious metals. The Quarterly Review of Economics and Finance. 51, 436-441.

Hwang, E., Min, H-G, Kim,B-H., Kim, H. 2013. Determinants of stock market comovements among US and emerging economies during the US financial crisis. Economic Modelling 35, 338-348.

Kroner, K. F., and Sultan, J. 1993. Time dynamic varying distributions and dynamic hedging with foreign currency futures, Journal of Financial and Quantitative Analysis, $28,535-551$.

Lin, B., Wesseh Jr, P.K., Appiah, M.O. 2014. Oil price fluctuation, volatility spillover and the Ghanaian equity market: Implication for portfolio management and hedging effectiveness. Energy Economics 42, 172-182.

Ling, S., McAleer, M. 2003. Asymptotic theory for a vector ARMA-GARCH model. Econometric Theory 19, 278-308.

Ku, Y.H. , Chen, H.C., Chen, K.H. 2007. On the application of the dynamic conditional correlation model in estimating optimal time-varying hedge ratios, Applied Economics Letters 14, 503-509.

Malik, F., Ewing, B.T., 2009. Volatility transmission between oil prices and equity sector returns. International Review of Financial Analysis 18, 95-100.

Malik, F., Hammoudeh, S., 2007. Shock and volatility transmission in the oil, US and Gulf equity markets. International Review of Economics and Finance 16, 357-368. 
Mensi,W.,Beljid, M.,Boubaker, A., Managi, S. 2013. Correlations and volatility spillovers across commodity and stock markets: Linking energies, food and gold. Economic Modeling 32, 15-22.

Mensi, W.,Hammoudeh, S., Nguyen, D.K., Yoon, S-M, 2014. Dynamic spilllovers among major energy and cereal commodity prices. Energy Economics 43, 225-243.

Mollick, A.V., Assefa, T.A. 2013. US stock returns and oil prices: The tale from daily data and the 2008-2009 financial crisis. Energy Economics 36, 1-18.

Nazlioglu, S.,Erdem, C.,Soytas, U. 2013. Volatility spillover between oil and agricultural commodity markets. Energy Economics 36, 658-665.

Pan,, Z., Wang, Y., Yang, L. 2014. Hedging crude oil using refined product: A regime switching asymmetric DCC approach. Energy Economics 46, 472-484.

Sadorsky, P. 2012. Correlations and volatility spillovers between oil prices and the stock prices of clean energy and technology companies. Energy Economics 34, 248-255.

Sadorsky, P. 2014a. Modeling volatility and correlations between emerging market stock prices and the prices of copper, oil and wheat, Energy Economics 43, 72-81.

Sadorsky, P. 2014b Modelling volatility and conditional correlations between socially responsible investments, gold and oil. Economic Modelling 38, 609-618

Serra, T. 2011. Volatility spillovers between food and energy markets: A semiparametric approach. Energy Economics 33, 1155-1164.

Serra, T., Zilberman, D., Gil, J.M., 2011. Price volatility in ethanol markets. Europ. Rev. Agric. Econ. 38, 259-280.

Silvennoinen, A., Thorp, S., 2013. Financialization, crisis and commodity correlation dynamics. Journal of International Financial Markets, Institutions and Money 24, 42-65.

Tang, K., Xiong, W. 2009. Index investment and the financialization of commodities. Financial Analysts Journal 68, 54- 74.

The Economist 2011. Why the tail wags the dog. http://www.economist.com/node/21525373

Van der Weide,R. 2002. GO-GARCH: a multivariate generalized orthogonal GARCH model. Journal of Applied Econometrics, 17(5):549-564.

Van der Weide, R. 2006. Wake me up before you GO-GARCH. Tinbergen Institute Discussion Paper 2006/03. 
Vivian, A., Wohar, M.E., 2012. Commodity volatility breaks. Journal of International Financial Markets, Institutions and Money 22, 395-422.

World Gold Council, 2013. Gold and currencies: hedging foreign-exchange risk. London, January.

Yu, J., 2005. On leverage in a stochastic volatility model. Journal of Econometrics 127, $165-178$.

Zhang, K, Chan, L. 2009. Efficient factor garch models and factor-dcc models. Quantitative Finance, 9(1):71-91.

Zhang, Z., Lohr, L., Escalante, C., Wetzstein, M., 2009. Ethanol, corn, and soybean price relations in a volatile vehicle-fuels market. Energies 2, 320-339. 
Figure 1. Time series plots

EM (\$US)

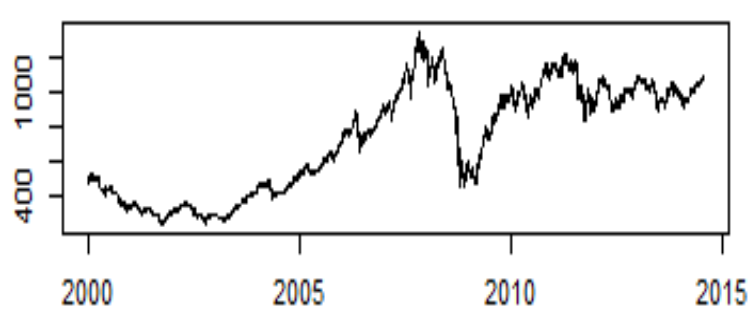

VIX

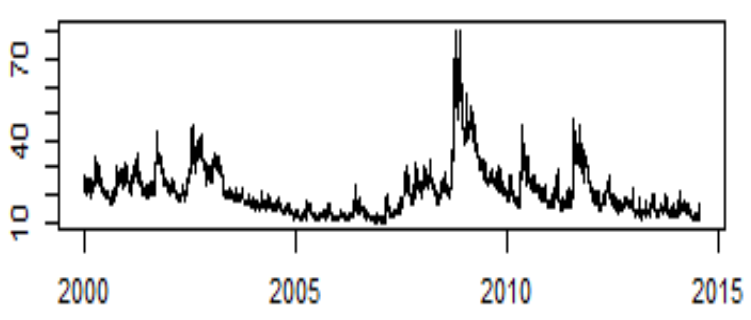

BONDS (\$US)

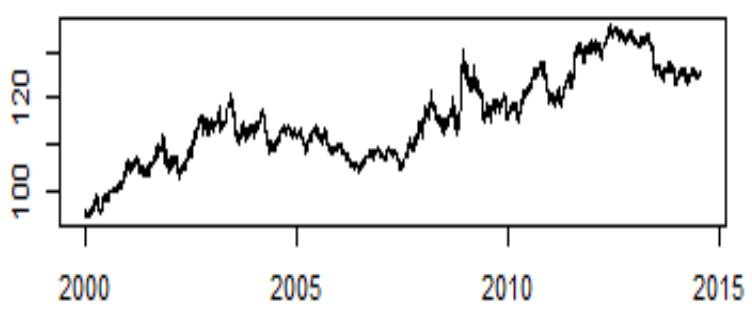

OIL (\$US/bbl)

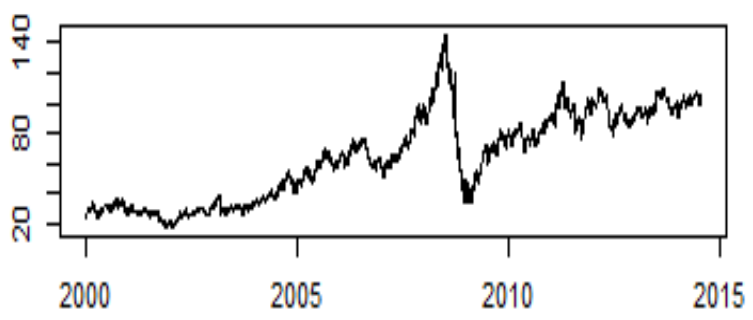

GOLD (\$US/ounce)

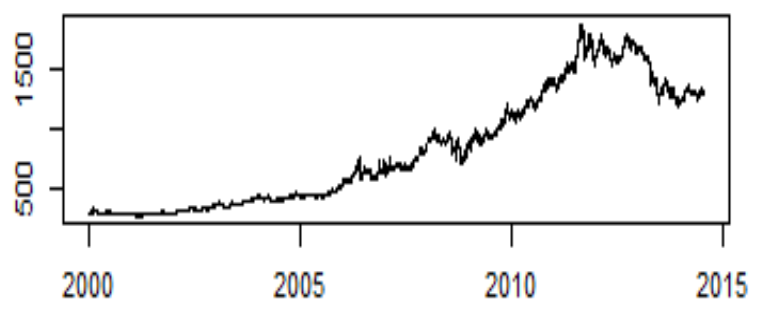


Figure 2. Squared daily returns

EM daily squared returns

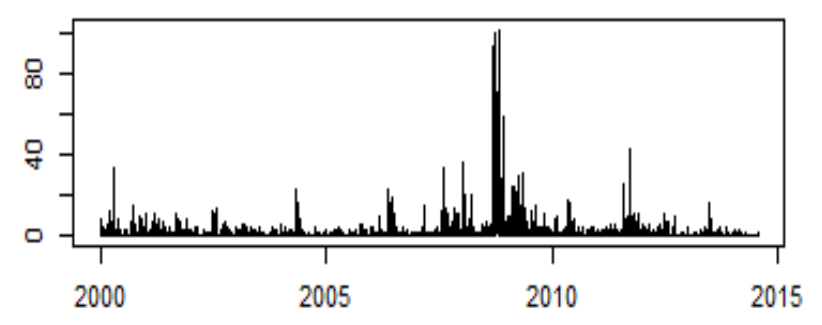

VIX daily squared returns

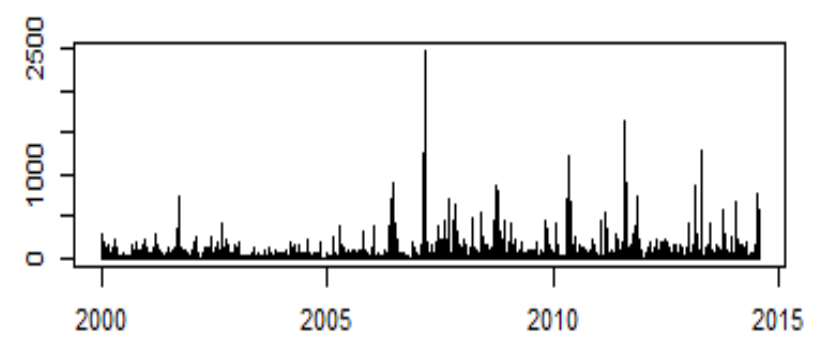

OIL daily squared returns

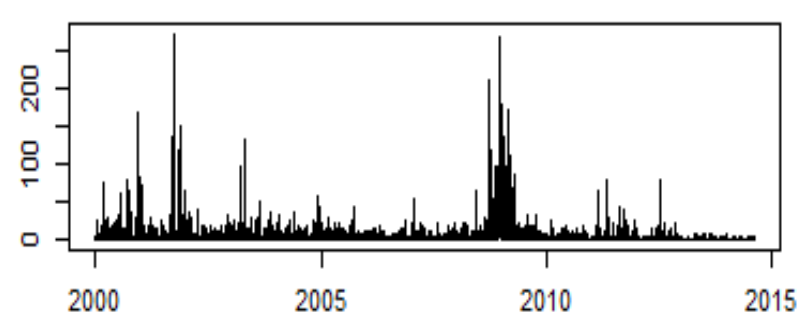

GOLD daily squared returns

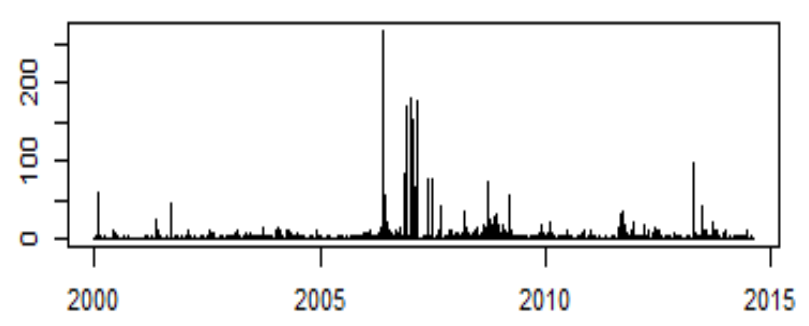

BONDS daily squared returns

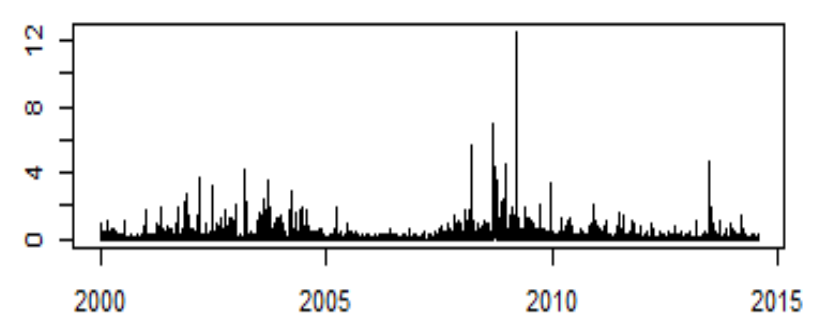


Figure 3. Rolling one-step-ahead conditional correlations

\section{Dynamic conditional correlations: EM/OIL}

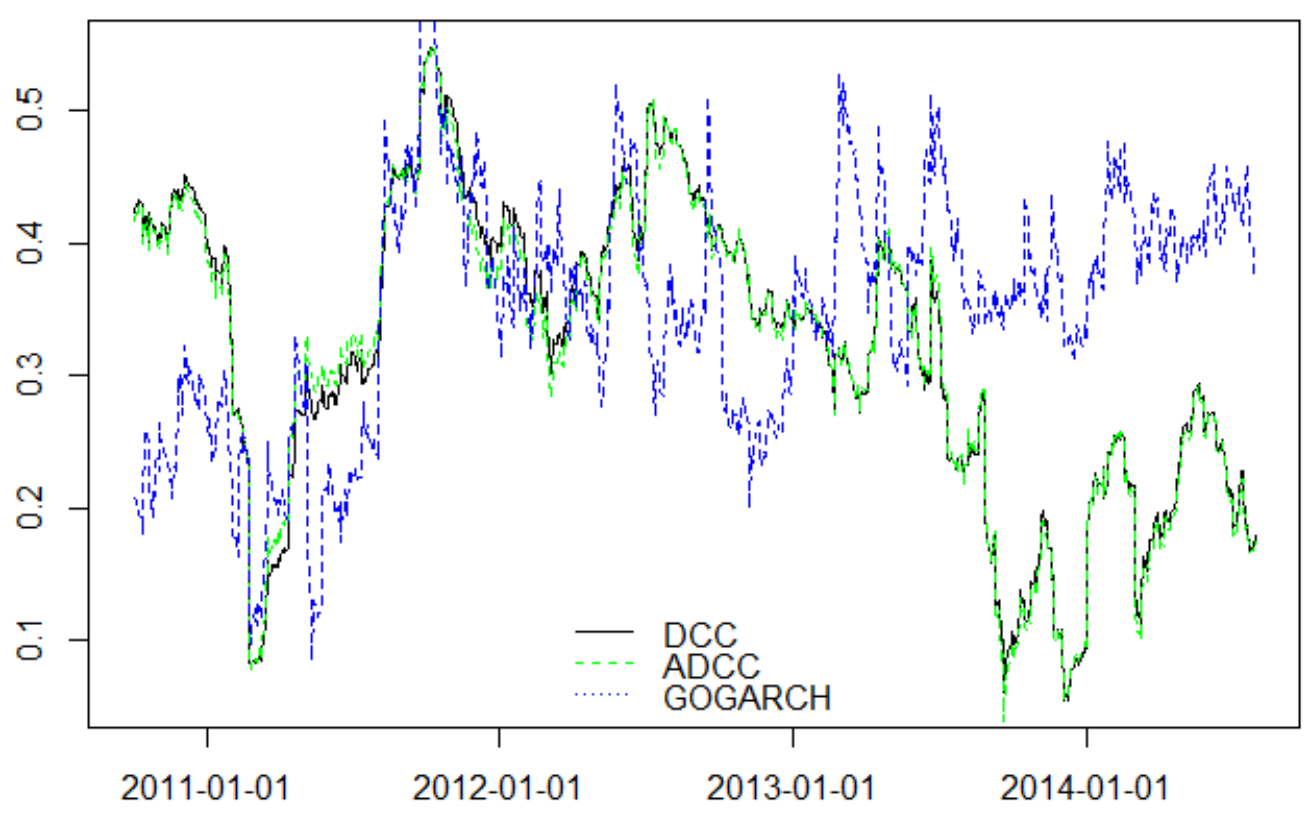

Dynamic conditional correlations: EM/VIX

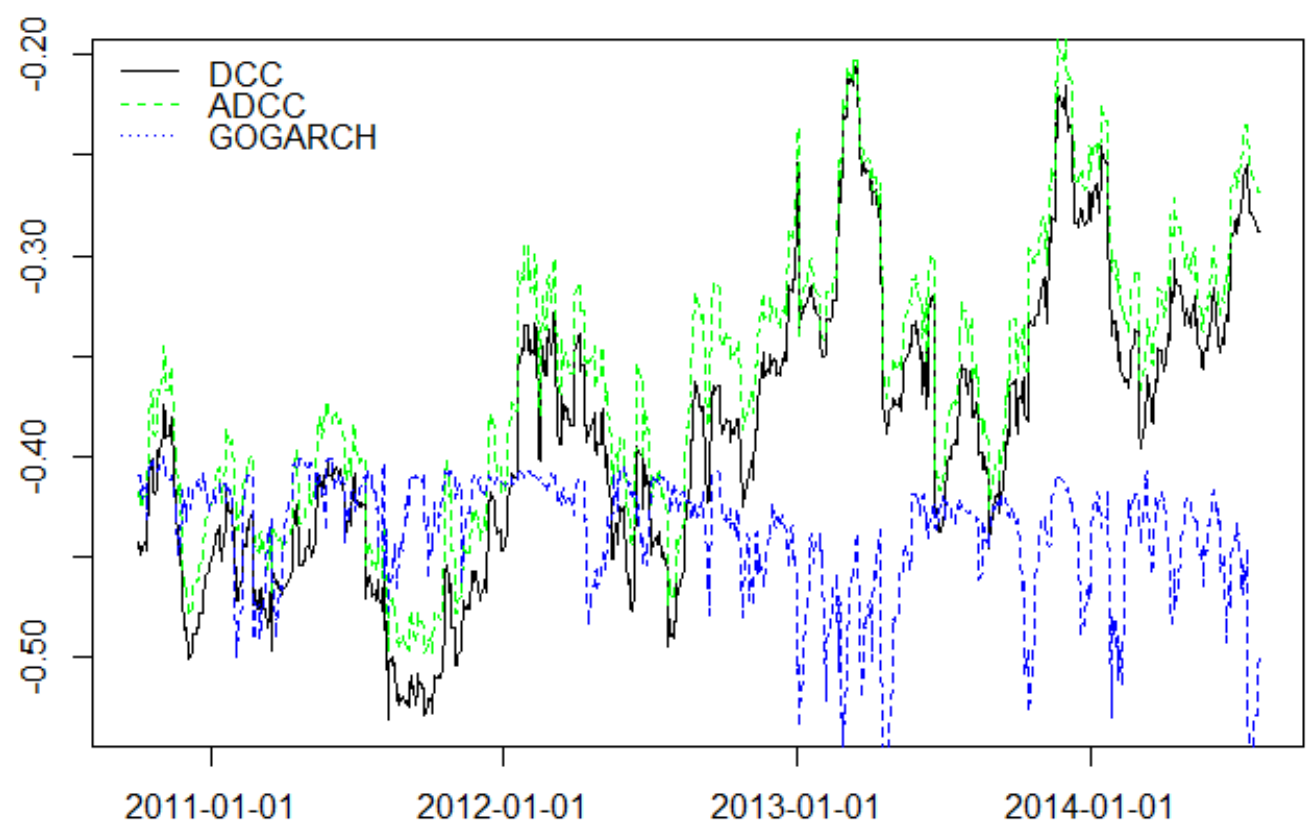


Dynamic conditional correlations: EM/GOLD

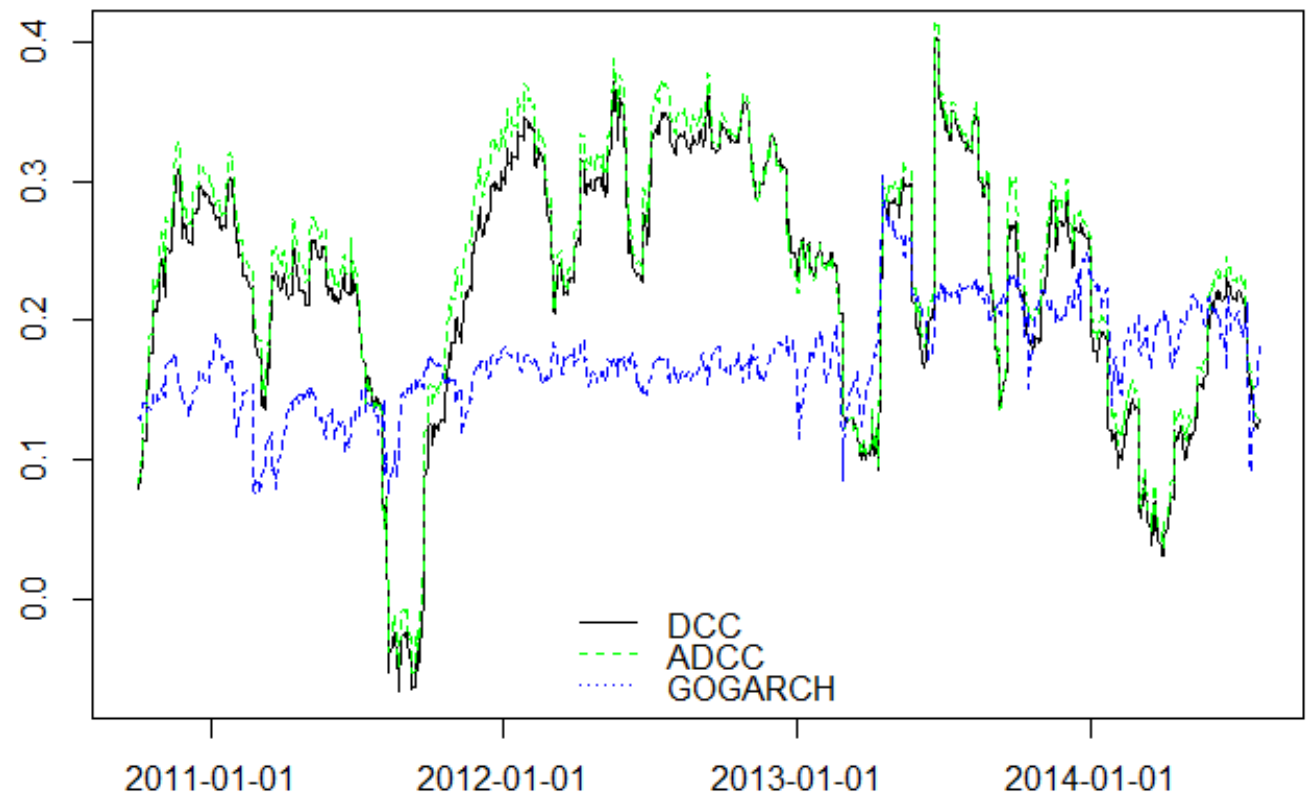

Dynamic conditional correlations: EM/BONDS

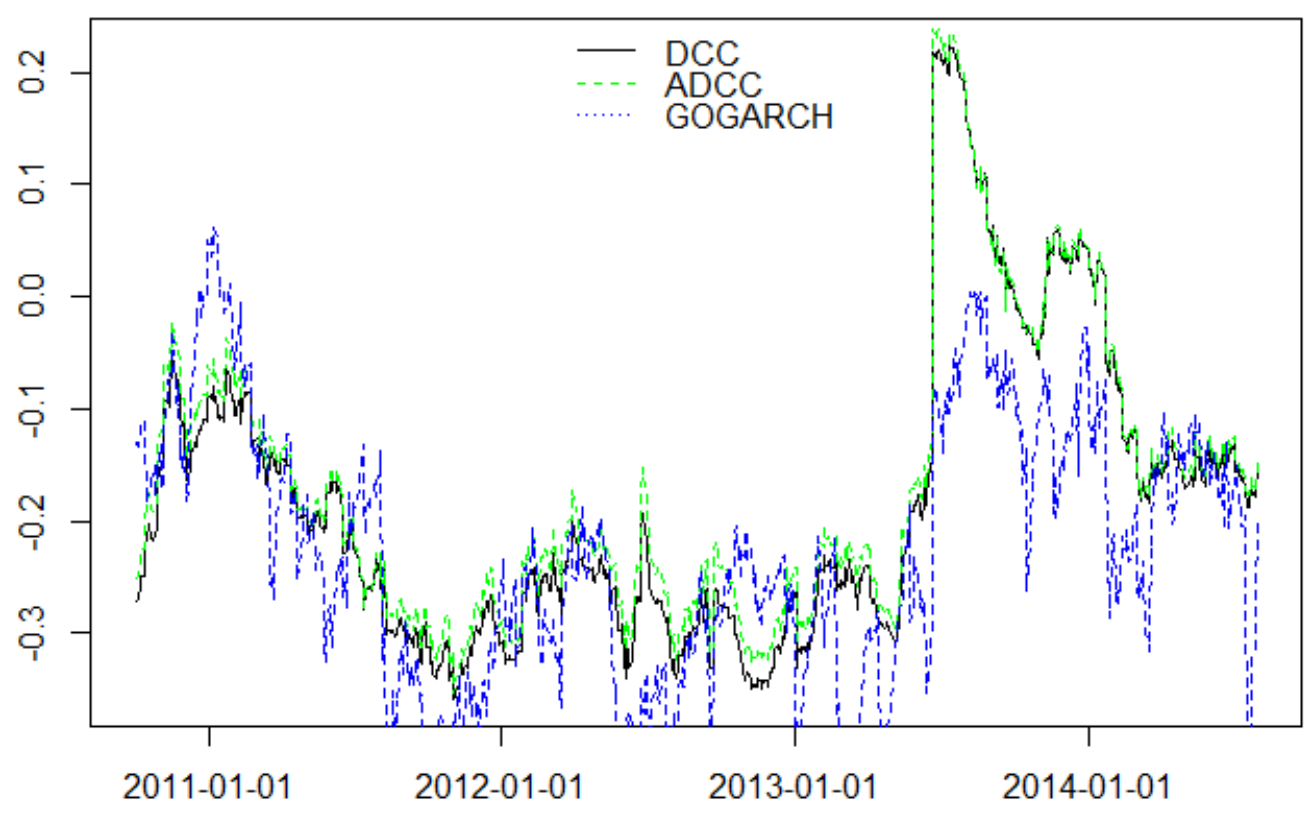


Figure 4a. News impact correlation surface between EM and VIX - DCC

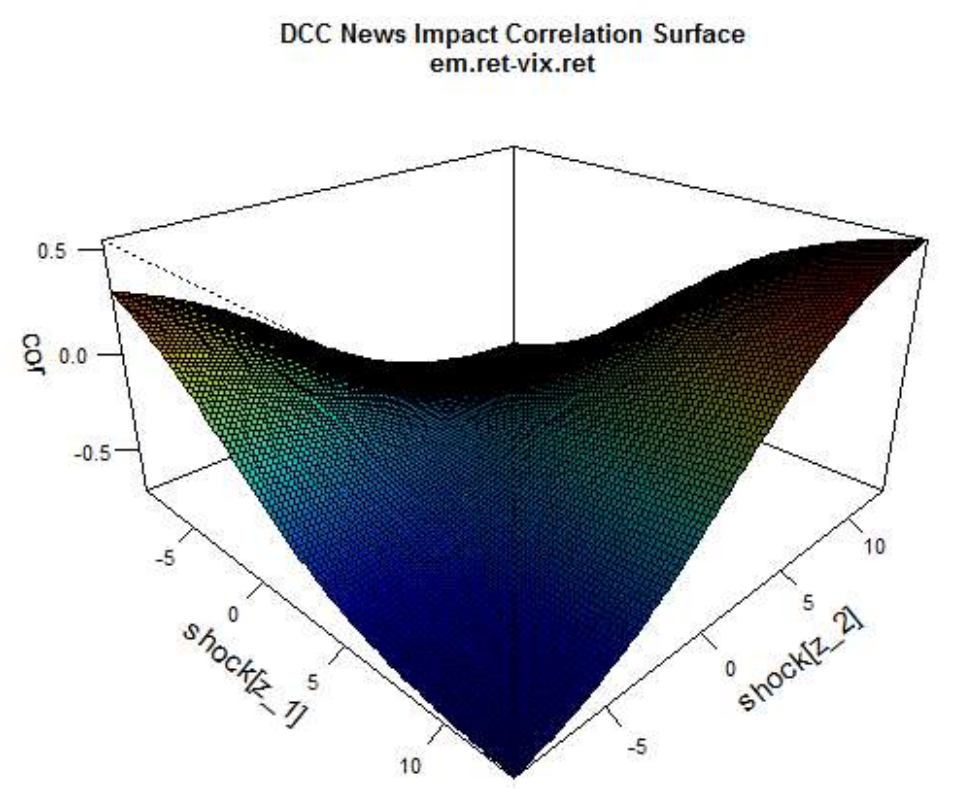


Figure 4b. News impact correlation surface between EM and VIX - ADCC

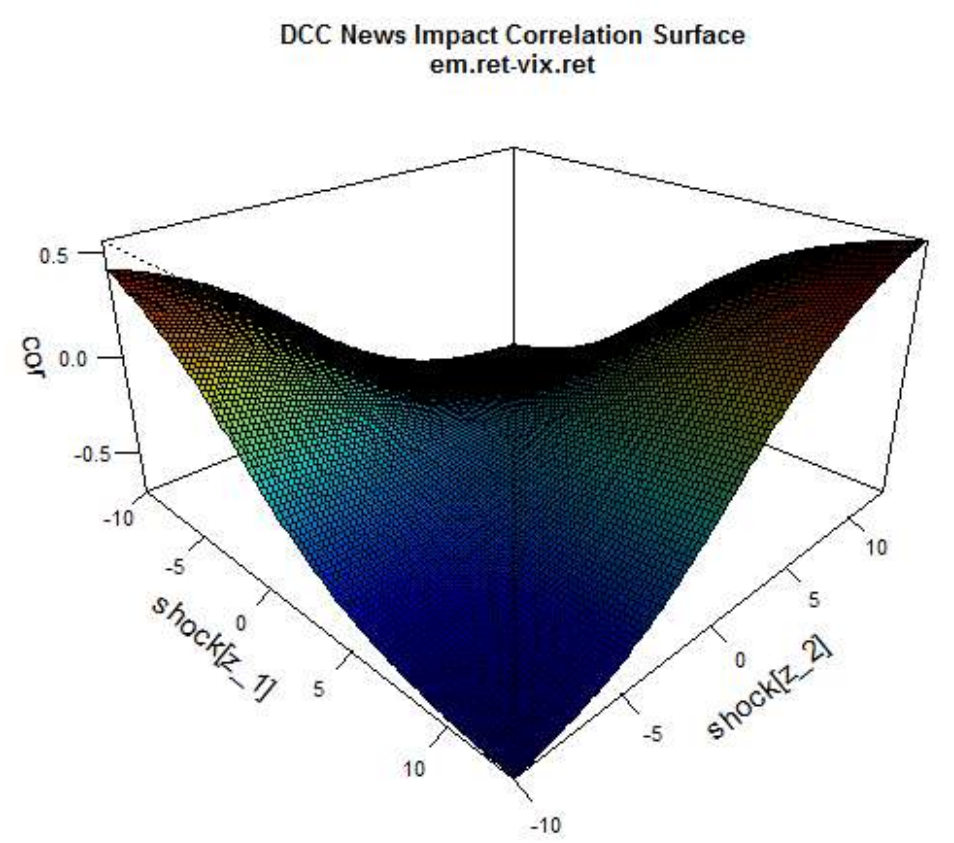


Figure 4c. News impact correlation surface between EM and VIX - GO-GARCH

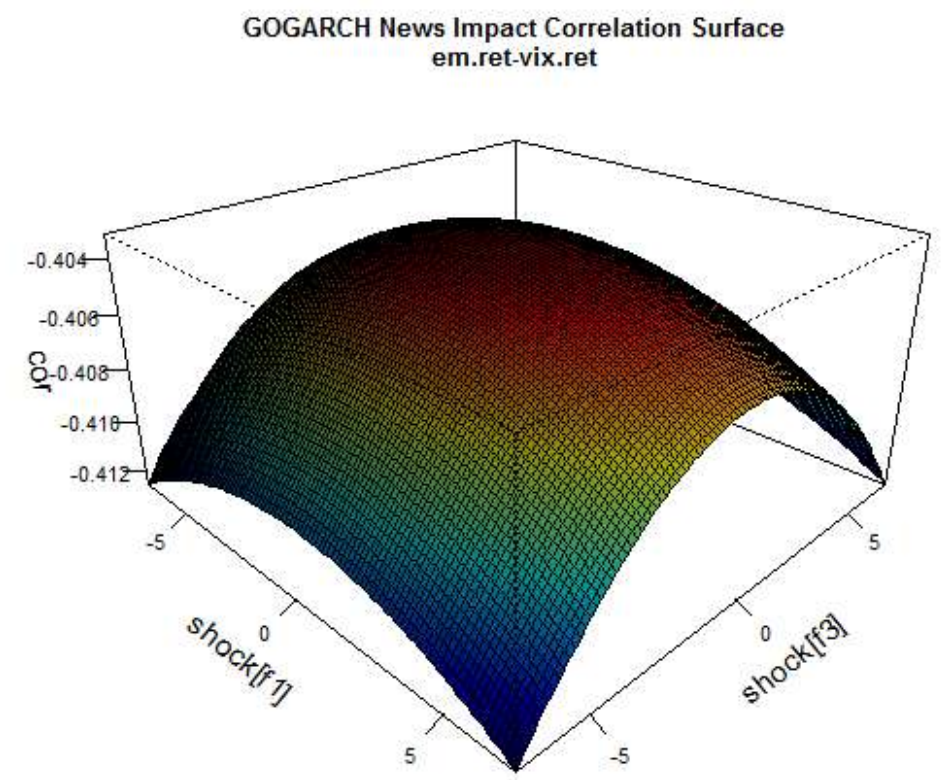


Figure 5. Rolling one-step-ahead optimal hedge ratios

Optimal hedge ratio: EM/OIL

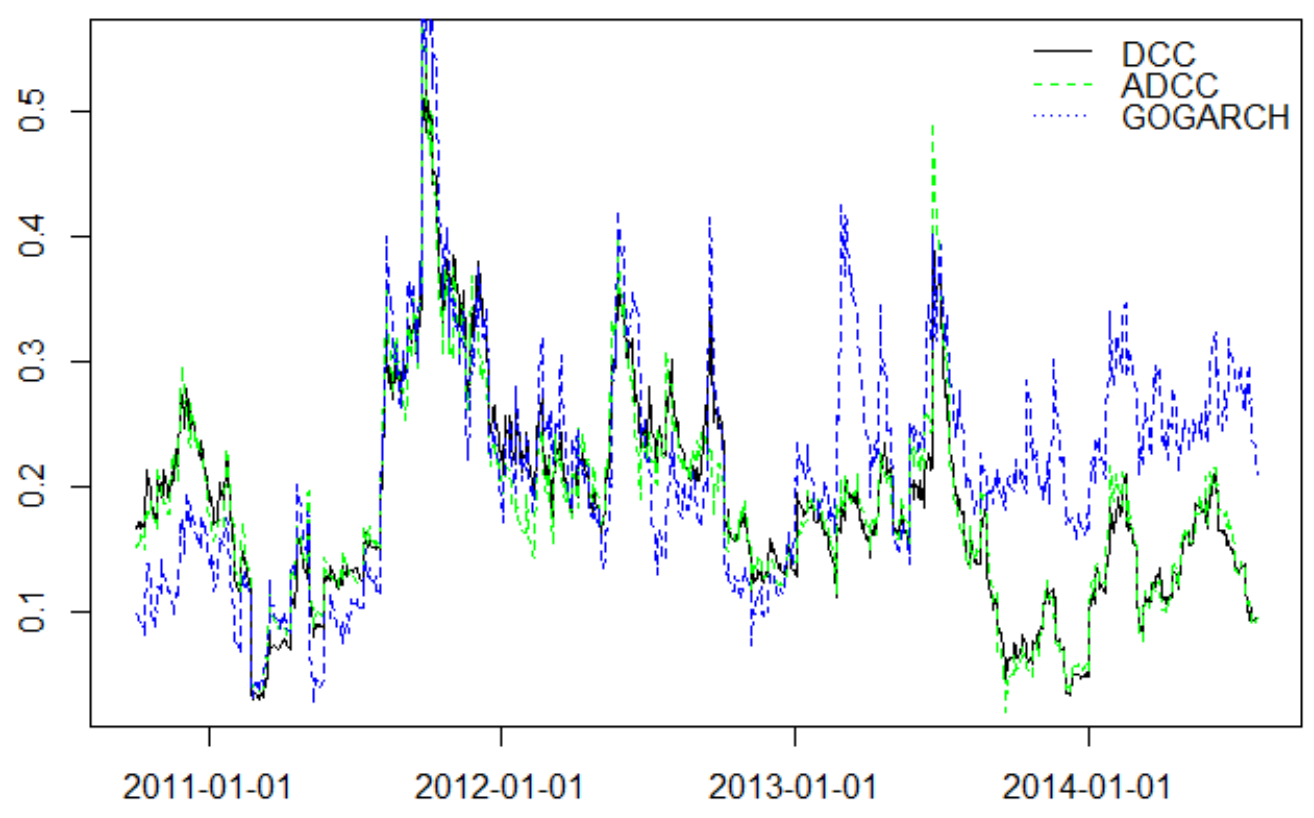

Optimal hedge ratio: EM/VIX

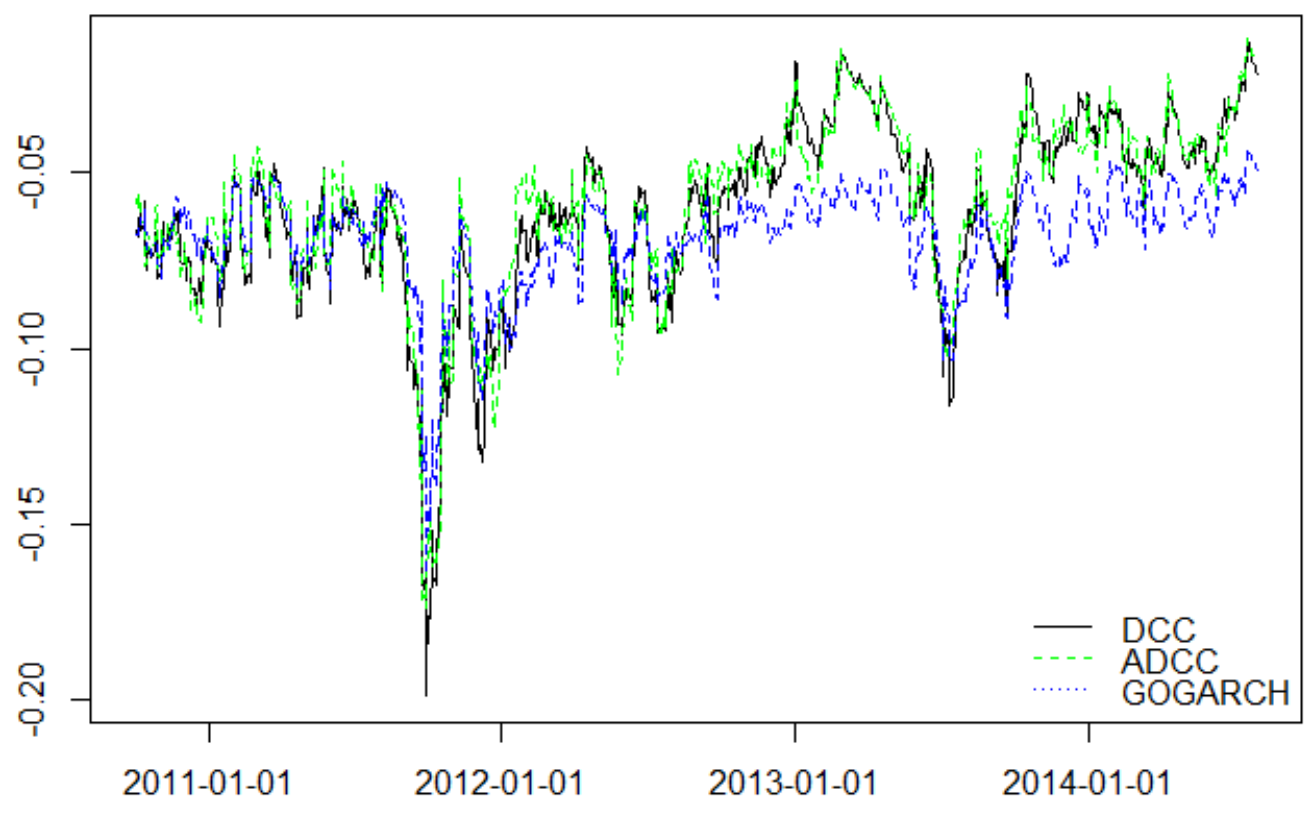


Optimal hedge ratio: EM/GOLD

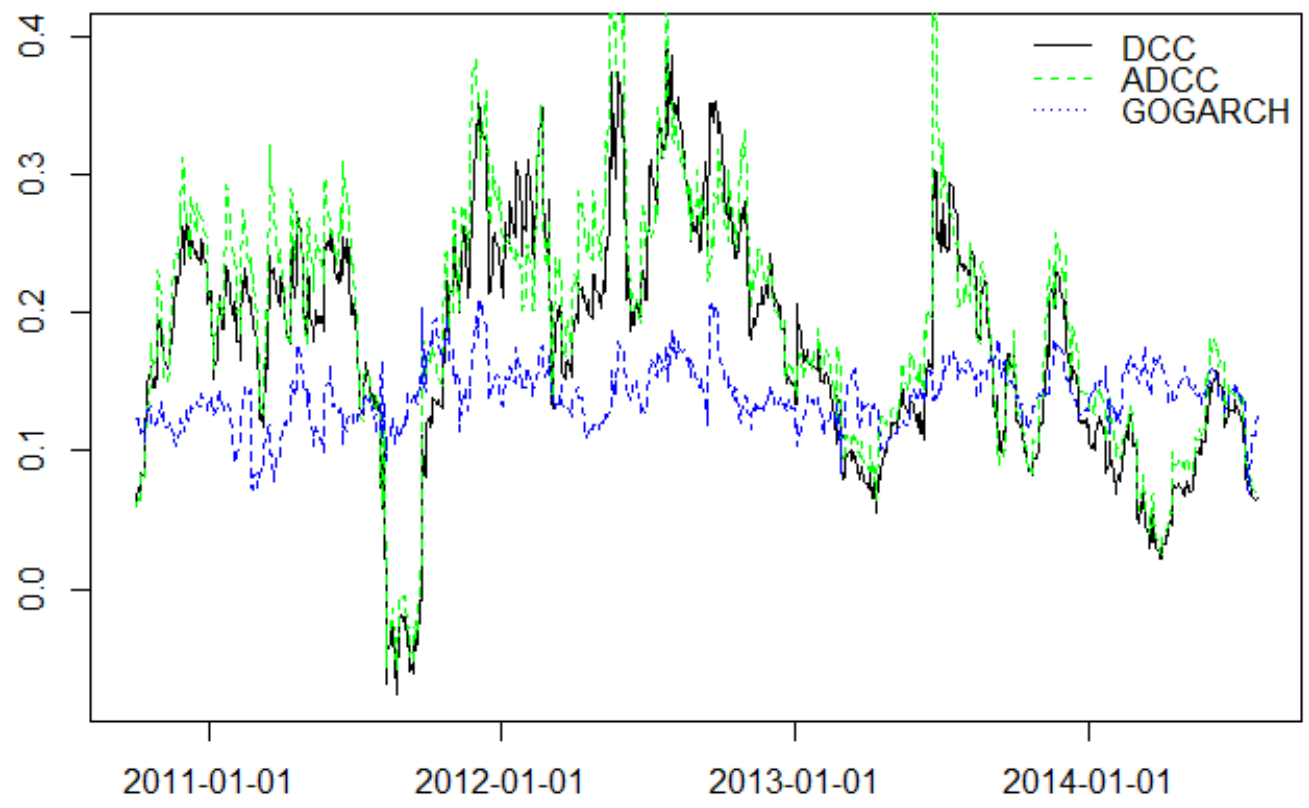

Optimal hedge ratio: EM/BONDS

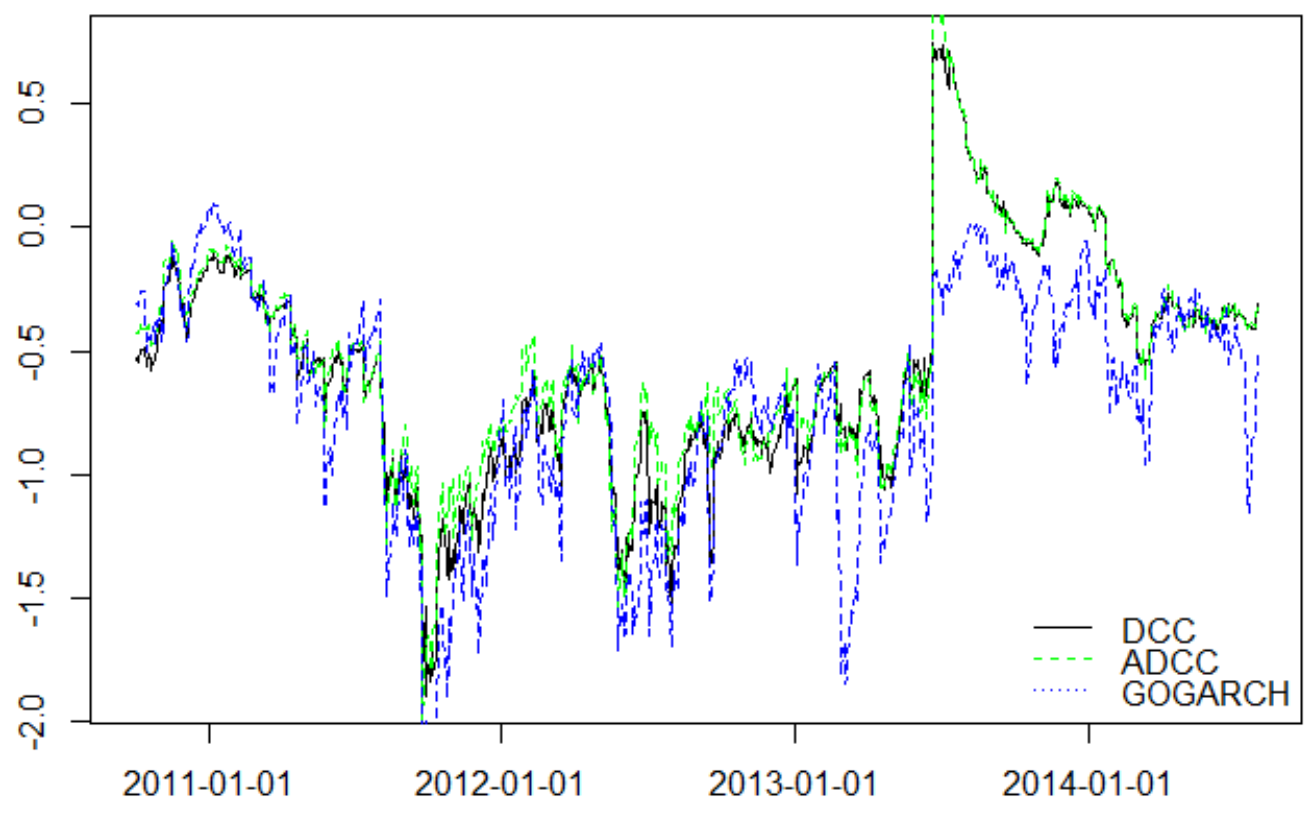

